\title{
Review
}

Wei Zien Gan' / Valsala Ramachandran ${ }^{1}$ / Crystale Siew Ying Lim² / Rhun Yian Koh

\section{Omics-based biomarkers in the diagnosis of diabetes}

\author{
${ }^{1}$ Division of Applied Biomedical Science and Biotechnology, School of Health Sciences, International Medical University, 57000 \\ Kuala Lumpur, Malaysia \\ ${ }^{2}$ Department of Biotechnology, Faculty of Applied Sciences, UCSI University Kuala Lumpur, 56000 Kuala Lumpur, Malaysia \\ ${ }^{3}$ Division of Applied Biomedical Science and Biotechnology, School of Health Sciences, International Medical University, 57000 \\ Kuala Lumpur, Malaysia, Phone: +60327317207, E-mail: rhunyian_koh@imu.edu.my
}

\begin{abstract}
:
Diabetes mellitus (DM) is a group of metabolic diseases related to the dysfunction of insulin, causing hyperglycaemia and life-threatening complications. Current early screening and diagnostic tests for DM are based on changes in glucose levels and autoantibody detection. This review evaluates recent studies on biomarker candidates in diagnosing type 1, type 2 and gestational DM based on omics classification, whilst highlighting the relationship of these biomarkers with the development of diabetes, diagnostic accuracy, challenges and future prospects. In addition, it also focuses on possible non-invasive biomarker candidates besides common blood biomarkers.
\end{abstract}

Keywords: biomarkers, diabetes, gestational diabetes mellitus, omics, type 1 diabetes, type 2 diabetes DOI: $10.1515 / \mathrm{jbcpp}-2019-0120$

Received: May 3, 2019; Accepted: October 7, 2019

\section{Introduction}

Diabetes mellitus (DM) is a group of metabolic diseases resulting in hyperglycaemic conditions. It is associated with defects in either insulin production, insulin action, or both [1]. As this disease progresses, it may lead to the dysfunction of various organs, most commonly the eyes, blood vessels, kidneys, heart, and nerves [1]. Globally, according to the World Health Organisation (WHO), the prevalence and incidence of diabetes has increased from 108 million in 1980 to 422 million in 2014 [2]. In the past decade, the International Diabetes Federation (IDF) illustrated that the estimated prevalence worldwide has continuously grown each year (366 million in 2011 [3], 371 million in 2012 [4], 382 million in 2013 [5], 415 million in 2015 [6], and 451 million in 2017 [7]). It is expected to rise to 552 million, 592 million, 642 million, and 693 million people diagnosed with diabetes by the years 2030, 2035, 2040, and 2045, respectively [3], [5], [6], [7]. In contrast, in 2013 approximately 45.8\% diabetic patients remain undiagnosed [8] increasing to $46.5 \%$ in 2015 [6], followed by $49.7 \% 2$ years later [7]. In addition, from 2013 to 2017 diabetes accounted for $8.4 \%-12.8 \%$ of the all-cause mortality of people globally [6], [7], [9].

The vast majority of DM cases fall into three categories: type 1 (T1D); type 2 (T2D); and gestational (GDM). Of the three types of DM, the two most commonly diagnosed DM are T2D (about $90 \%$ of cases) and T1D (about 10\% of cases) [1]. T2D is attributed to insulin resistance at targeted organs and partial insulin production deficiency by pancreatic $\beta$-cells, usually leading to obesity [1]. Global T2D is prevalent mostly among those living in low-tomiddle income countries [2]. T1D is the outcome of the autoimmune destruction of pancreatic $\beta$-cells, resulting in an absolute deficiency in insulin production [1]. The majority of T1D patients are males aged between 5 and 7 years old [1], [10], [11]. Diabetic ketoacidosis is associated more with T1D than T2D, but is more severe in T2D [12]. The third type of diabetes, GDM, is diagnosed mostly during the second or third trimester of pregnancy, characterised by the onset of any degree of impaired glucose tolerance [1]. It is a common complication during pregnancy, occurring in 1 to $14 \%$ of all pregnancies [1]. However, the onset of GDM in these mothers is a great risk factor, not only for the development of T2D in their later years, but also birth injuries, macrosomia, and hyperinsulinism in their children [13], [14], [15].

Current screening and diagnostic methods for DM are based solely on glucose metabolism, such as fasting plasma glucose (FPG), 2-h plasma glucose (2-h PG) in a 75-g oral glucose tolerance (OGT), or the glycated haemoglobin $\left(\mathrm{HbA}_{1 \mathrm{c}}\right)$ test [16]. However, these tests are time-consuming and inconvenient, as if the test result 
is within the diabetic range [16], a confirmatory laboratory test must be done on another day [17] as some methods only reflect glucose homeostasis at a single time-point [16], [18]. Biological and analytical variations, coupled with a lack of universal glucose cut-off values in assessing DM [16], [18], may lead to missed diagnoses, such as where approximately $10 \%$ of patients remained undiagnosed with diabetes using the 2-h PG in a 75-g OGT [19], or misdiagnoses, such as where certain ethnicities (Asians, African-Americans, American Indians and Hispanics) have $0.4 \%$ higher $\mathrm{HbA}_{1 \mathrm{c}}$ values compared to non-Hispanic whites at similar glycaemic levels [16], [20].

With the exponential increase in the incidence of people diagnosed with DM, rapid biomarkers for use in the early diagnosis of diabetic patients are therefore in high demand. These biomarkers could also facilitate a shift from the current standard-of-care by enabling earlier intervention or treatment.

Biomarkers are measurable biological characteristics to differentiate normal from pathological states or response to a therapeutic drug given [21], [22]. Thus, the sensitivity and specificity of a biomarker to the disease it is meant to indicate is of utmost importance [23]. Whilst there have been advances in understanding the pathogenesis of diabetes [24], biomarkers that can effectively reflect pancreatic $\beta$-cell function and mass are still of poor quality. Thus, omics-based classifications (genomics, transcriptomics, proteomics, metabolomics and metagenomics) have recently gained interest as sources of diagnostic biomarkers [25], [26], the current applications and potential of which are the foci of this review paper.

\section{Classical versus omics-based approaches}

Owing to the current advancement in high-throughput technologies, an omics-based approach has gained much interest in biological research [27]. An omics-based approach uses omics-based technologies to detect genes, RNAs, proteins, and metabolites at a universal level, while the integration of these techniques is known as systems biology [28]. It is hoped that an omics-based approach may provide researchers with a better understanding of molecules and their changes in normal physiological and disease processes as a whole [28].

Traditionally, a classical-based approach uses reductionist or hypothesis-driven methods to understand a biological system [27]. Here, only a few targeted molecules are studied to identify their suspected functional structure [27]. On the other hand, an omics-based approach uses holistic, non-bias and integrative methods for a better understanding of the whole process [27]. The main advantage of using omics-based technologies is that researchers are now able to investigate multiple molecules (genes, proteins, and metabolites) simultaneously and obtain a large amount of data, instead of only a few targeted data, in a short period of time [27]. This enables researchers to clarify the molecular constituents associated with the underlying cellular processes and how it changes over time, as well as under varying conditions such as disease-state compared to healthy individuals [27]. It also helps to reveal the dynamic functions and interactions between them [27]. Thus, in order for a molecule (gene, protein or metabolite) to serve as a diagnostic biomarker, its expression profile ideally discriminates between cases and controls for a diseased state [29].

\section{Genomics}

Genomics is a systematic study of the genome present in a cell or an organism, including its structure, expression and function. It also covers the genetic variants such as single nucleotide polymorphisms (SNPs) and chromosomal abnormalities associated with the disease, including response to treatment or even patient prognosis [28]. The tools often used in genomic studies include genotype microarrays [30], next generation sequencing for whole-genome sequencing [31] and exome sequencing [32].

\section{Type 1 diabetes mellitus}

Gene mutation plays a crucial role in T1D pathogenesis. It is hypothesised that single-nucleotide polymorphisms (SNPs) in the major histocompatibility complex (MHC) class II gene region of CD4 T cells, mainly the HLA-DR3/4 and HLA-DQ2/8 alleles located on chromosome 6p21.3 region, are responsible for T1D-associated autoantibody production against pancreatic islet cells [33], [34]. HLA-DR3 is related to the glutamic acid decarboxylase (GAD) autoantibody (GADA) and the transglutaminase autoantibody (TGA), while HLA-DR4 is related to the insulinoma-2-associated (IA-2A), zinc transporter 8 (ZnT8A), gastric parietal cell (PCA), thyroid peroxidase (TPOA), and 21-hydroxylase (21-OHA) autoantibodies [34]. Genotyping array studies of the HLA-DR and HLA-DQ alleles found that the strongest allelic associations with T1D are within the HLA-DR $\beta 1-$ HLA-DQ $\alpha 1-H L A-D Q \beta 1$ region [35]. The amino acid mutation points associated with T1D risk are HLA-DR 1 
positions 13 (histidine and serine) and 71 (lysine), as well as HLA-DQ 1 position 57 (alanine) [36]. For HLADR $\beta 1$ point mutations, at position 13, histidine and serine are tagged for HLA-DR4 and HLA-DR3, respectively, while an SNP at position 71 (lysine) is tagged for both HLA-DR [36].

Studies also show that SNPs in the MHC class I gene region of CD8 T cells remain major genetic risk determinants of T1D, but have linkage disequilibrium towards HLA-DR/DQ alleles. Interestingly, the HLA-C gene does not reflect linkage disequilibrium towards HLA-DR/DQ haplotypes [36]. Furthermore, using immunochip, a customised genotyping array, SNPs at non-MHC regions, as detected in the serum, were found to be associated with the production of these autoantibodies (Table 1). Therefore, these loci could be used as candidates for early screening of T1D.

Table 1: Association between autoantibody production and single-nucleotide polymorphisms at non-major histocompatibility complex regions.

\begin{tabular}{llr}
\hline Autoantibodies & Locus & References \\
\hline GADA & IFIH1/2q24, 3q28/LPP & [34], [37] \\
IA-2A & IFIH1/2q24, PTPN22/1p13, BACH2/6q15, IL10/1q32, IFIH1/2q24, & [34], [37] \\
& IL27/16p11, CTLA4/2q33, 1q23/FCRL3, 11q13/RELA & [34], [37] \\
21-OHA & IFIH1/2q24, IL2/4q27 & [34], [37] \\
PCA & IFIH1/2q24, PTPN22/1p13, SH2B3/12q24, SKAP2/7p15, IL2RA/10p15, & \\
& INS/11p15, UBASH3A/21q22, 2q24/IFIH1 & [34], [37] \\
TPOA & IFIH1/2q24, PTPN22/1p13, SH2B3/12q24, BACH2/6q15, CD69/12p13, \\
& ERBB3/12q13, SIRPG/20p13 & [34], [37] \\
TGA & CTLA4/2q33, 3q28/LPP & [34], [37] \\
\hline
\end{tabular}

GADA, Glutamic acid decarboxylase autoantibody; IA-2A, insulinoma-2-associated autoantibody; 21-OHA, 21-hydroxylase autoantibody; PCA, gastric parietal cell autoantibody; TPOA, thyroid peroxidase autoantibody; TGA, transglutaminase autoantibody; ZnT8A, zinc transporter 8 autoantibodies.

\section{Type 2 and gestational diabetes mellitus}

SNPs in gene regions are associated with the risk of T2D and GDM. According to the NHGRI-EBI catalog of published genome-wide association studies (GWAS), many genes have been reported to be highly-associated with T2D predisposition, while significantly less were reported to be associated with GDM predisposition. Given that pathophysiological similarities exist between T2D and GDM with common genetic origin, we review some of the genes that are highly-associated with T2D predisposition. The selected genes are: cyclin-dependent kinase 5 regulatory subunit associated protein 1-like 1 (CDKAL1); potassium voltage-gated channel subfamily $\mathrm{Q}$ member 1 (KCNQ1); and cyclin dependent kinase inhibitors 2A/B (CDKN2A/B). These genes, as well as their SNPs, are associated with the risk of both T2D and GDM [38], [39]. Found to be expressed in both blood and diabetic targeted tissues [38], these SNPs could serve as candidate blood-based biomarkers for T2D and GDM.

SNPs of CDKAL1, a gene on chromosome region 6p22.3 [38], are believed to be associated with impaired first phase insulin output in T2D and GDM [40], [41], [42]. Impaired cyclic adenosine monophosphate(cAMP)induced insulin output is seen in the CDKAL1 $1^{(-/)}$human embryonic stem cells differentiated into pancreatic $\beta$-cells [43], where the misreading of the Lys-coding codon in proinsulin reduces glucose-stimulated proinsulin synthesis whilst increasing endoplasmic reticulum stress [44]. CDKAL1 plays a critical role in biosynthesising a part of $\mathrm{RRNA}^{\mathrm{Lys}}$ and is required for the translation of Lys residues in proinsulin at the ribosome [44]. In terms of diabetic complications, SNPs of the CADKAL1 region are also linked to the risk of developing obesity [45] and diabetic retinopathy [46] but the pathophysiological processes have yet to be reported.

The KCNQ1 gene, located at chromosome 11p15.4 region [38], encodes for a pore-forming $\alpha$-subunit termed $\mathrm{K}_{\mathrm{v}} 7.1$, which is a potassium voltage-gated $\left(\mathrm{K}_{\mathrm{v}}\right)$ channel protein [47], [48]. SNPs of the KCNQ1 region are hypothesised to be associated with impaired insulin secretion and glucose intolerance, but not the maturation of pancreatic $\beta$-cells for insulin production in T2D and GDM [42], [43], [47]. KCNQ1 mutations result in greater insulin output impairment than CDKAL1 mutations found in human embryonic stem cells that have been differentiated to pancreatic $\beta$-cells [43]. The KCNQ1 gene and its protein subunit has been known for its role in generating outward-rectifying $\mathrm{K}^{+}$current flow during the repolarisation and post-repolarisation phase in pancreatic $\beta$-cell action potentials, causing insulin and GLP-1 exocytosis from pancreatic $\beta$-cells and intestinal L-cells, respectively [48], [49], [50]. In terms of diabetic complications, SNPs of the KCNQ1 region are hypothesised to be associated with the risk of developing diabetic nephropathy and hypertension [51], [52]. 
The CDKN2A/B genes, located at the chromosome 9p21.3 region [38], encode for three proteins: p16 inhibitors of cyclin dependent kinase $4\left(\mathrm{p} 16^{\mathrm{INK} 4 \mathrm{~A}}\right)$, p14 alternative reading frame (p14 $\left.{ }^{\mathrm{ARF}}\right)$ and $\mathrm{p} 15$ inhibitors of cyclin dependent kinase 4 ( $\mathrm{p} 15^{\mathrm{INK} 4 \mathrm{~B}}$ ) proteins [53]; but only the $\mathrm{p} 16^{\mathrm{INK} 4 \mathrm{~A}}$ protein is seen to be expressed in pancreatic $\beta$-cells [54], [55], [56]. The CDKN2A/B genes and their proteins are known for their roles in controlling cell-cycle progression and influence tumorigenesis, senescence, and aging [53]. p16 ${ }^{\mathrm{INK} 4 \mathrm{~A}}$ protein expression in pancreatic $\beta$-cell inhibits its proliferation and regeneration, while possibly altering its function related to insulin secretion [54], [55]. SNPs within the CDKN2A/B regions are hypothesised to be associated with a reduction in pancreatic $\beta$-cell mass, proliferation and function in T2D as well as GDM [39], [57]. In terms of diabetic complications, SNPs of the CDKN2A/B region and mutations of its protein, $\mathrm{p} 16^{\mathrm{INK} 4 \mathrm{~A}}$ might be associated with a risk in developing obesity and cardiovascular disease [58], [59]. Therefore, SNPs within these gene regions might serve as candidate biomarkers for T2D and GDM risks. However, these genes were not studied using genomics tools, hence more studies could be done on the association of the SNPs within these genes and the risk factors of T2D and GDM, they should be considered carefully before confirming them as candidates for risk biomarkers.

\section{Transcriptomics}

Transcriptomics focuses on examining total RNA profiles: coding and non-coding RNAs expressed in a cell or an organism. Transcriptomics, defined as the product in the cell or particular tissue that is transcribed from the genome, includes both the qualitative and quantitative study of RNAs present, as well as the functional roles of these RNAs, such as in structure and regulation [28]. The tools that are normally associated in this study include different types of RNA microarrays [60] and RNA sequencing [61], which can also combine with polymerase chain reaction $(\mathrm{PCR})$ technologies.

\section{Type 1 diabetes mellitus}

MicroRNA (miRNA) are small non-coding RNA which play an important role in gene regulation at the mRNA level by binding to mRNA, causing translational inhibition [62]. Each miRNA regulates different biological functions and is expressed differently in diseased-state compared to healthy individuals [63]. In pancreatic $\beta$ cells, the major T1D autoantigens (IA-2, IA-2 $\beta$, and GAD65) are regulated by miRNA (mostly from chromosomal location 14q32). Using quantitative real-time PCR (qRT-PCR) analysis, the overexpression of miR-665 was found to reduce the production of the IA- 2 antigen, while overexpression of miR-342 reduced the production of not only the IA- 2 but also the IA- $2 \beta$ antigens. Overexpression of miR-370 reduces expression of the GAD65 antigen [64].

Recently, by using miRNA microarray, followed by qRT-PCR validation, a study showed that miRNA in the exosomes in blood plasma, such as miR-16-5p, miR-302d-3p, and miR-574-5p, were downregulated [65] and involved in the regulation of second phase insulin output. In addition, using qRT-PCR quantification followed by miRNA sequencing, or miRNA microarray, these miRNAs in peripheral blood mononuclear cells (PBMCs) have been found to be specific to T1D: let-7, miR-103, miR-1260, miR-1274, miR-130a, miR-150, miR-20b, miR-720, miR-193a-5p, miR-16-5p, miR-142-5p, miR-133a-3p, miR-409-5p, miR-1271-5p, miR-501-3p, miR-486-5p, miR145-3p, and miR-3150-3p [66], [67], [68]. According to Massaro et al., miR-133a-3p is related to the T1D pathway [68], while other miRs are associated with diabetic retinopathy and nephropathy [68].

On the other hand, other miRNA such as, miR-375 and miR-21 play important roles in regulating cellular differentiation and apoptosis, respectively, of the $\beta$ islet cells [69], [70], [71]. Urinary miR-126 correlates well with $\mathrm{HbA}_{1 \mathrm{c}}(\mathrm{R}=-0.286)[69]$ and endothelial cell miR-126 are important in the development of retinopathy in diabetes, due to an increase in Spread-1 mRNA and protein levels, which in turn decrease endothelial progenitor cell colony formation, migration and proliferation [68], [72], [73]. However, these are not transcriptomics-based studies and researchers could look into it in the future.

The majority of miRNA is found in the plasma of T1D patients, while only a minority is found in other biological samples. As such, a possible correlation between plasma and urine miRNA associated to T1D is feasible. The upregulation or downregulation of miRNAs associated with T1D from different biological samples are listed in Table 2. 
Table 2: Different expression of microRNA levels associated with type 1 diabetes from different biological samples.

\begin{tabular}{lllr}
\hline Biological samples & Upregulation & Downregulation & References \\
\hline Plasma & MiR-21a, MiR-25, MiR-454-3p, & MiR-93, MiR-126, MiR-142-5p, & [67], [68], [69], [71], \\
& MiR-222-3p, MiR-144-5p, & MiR-146 & [74], [75], [76] \\
& MiR-375, MiR-345-5p, MiR-210, & & \\
Urine & MiR-133a-3p, MiR-486-5p & & \\
& MiR-21a, MiR-210 & MiR-126 & {$[69]$} \\
\hline
\end{tabular}

\section{Type 2 diabetes mellitus}

Similar to T1D, miRNA associates with the gene expression of insulin-resistant genes in T2D. There are many miRNAs found in plasma, such as miR-7, which regulates blood glucose and triglyceride levels by acting as a negative regulator [77], [78]. An overexpression of miR-7 reduces glucose-stimulated insulin secretion and pancreatic $\beta$-cell mass, and vice versa [78]. Another example is miR-802, which targets hepatocyte nuclear factor $1 \beta$ gene expression in liver cells [79]. Increasing miR-802 expression causes glucose intolerance, insulin resistance and stimulates hepatic gluconeogenesis [79]. Using qRT-PCR quantification followed by miRNA sequencing, or miRNA microarray, [66], [68] other miRNAs in PBMC specifically found in T2D patients include miR-140-3p, miR-199a-3p, miR-222, miR-30e, miR-451, miR-181c-3p, miR-148a-5p, and miR-143-3p. According to Massaro et al., miR-181c-3p and miR-148a-5p are related to T2D pathway [68]. Still other miRNAs are associated with other diseases, such as miR-503 is downregulated in T2D and obesity [80], while miR-126 is related to major cardiovascular events [81]. The miRNAs that are identified in the plasma of T2D patients are listed in Table 3.

Table 3: Different expression of microRNAs associated with type 2 diabetes from plasma.

\begin{tabular}{lllr}
\hline Biological samples & Upregulation & Downregulation & References \\
\hline Plasma & MiR-7, MiR-101, MiR-128, & MiR-126, MiR-320b, MiR-503, & [68], [77], [80], [82], \\
& MiR-130b-3p, MiR-143-3p, & MiR-572, MiR-423-5p, MiR-1249 & [83], [84], [85] \\
& MiR-374a-5p, MiR-433-5p, & & \\
& MiR-802, MiR-99b-5p, & & \\
& MiR-let-7d-3p & & \\
\hline
\end{tabular}

Besides blood, which is a common biological sample, saliva mRNA also serves as a biomarker to diagnose T2D. In saliva samples, by using transcriptomic diagnostics such as mRNA microarray, mRNAs of Kirsten rat sarcoma 2 viral oncogene homolog (KRAS), spermidine/spermine N1-acetyltransferase 1 (SAT1), solute carrier family 13, member 2 (SLC13A2), and transmembrane protein 72 (TMEM72) were found to be up-regulated, while mRNAs of epidermal growth factor receptor (EGFR) and proteasome subunit beta type-2 (PSMB2) were found to be downregulated in T2D patients [86]. The sensitivity and specificity of saliva mRNAs as potential diagnostic biomarkers for T2D are listed in Table 4. Combining the detection of the mRNAs of KRAS, SAT1, EGFR, and PSMB2, sensitivity could increase to $100 \%$ and specificity to $77 \%$ [86]. This shows that saliva mRNA profiles may serve as non-invasive biomarkers to diagnose T2D as an alternative to blood samples.

Table 4: Sensitivity and specificity of saliva mRNAs as diagnostic biomarkers for type 2 diabetes.

\begin{tabular}{lrrr}
\hline mRNA & Sensitivity, $\%$ & Specificity, $\%$ & References \\
\hline KRAS & 84.6 & 69.2 & {$[86]$} \\
SAT1 & 69.2 & 76.9 & {$[86]$} \\
SLC13A2 & 69.2 & 84.6 & {$[86]$} \\
TMEM72 & 46.2 & 100 & {$[86]$} \\
PSMB2 & 69.2 & 76.9 & {$[86]$} \\
EGRF & 100 & 46.2 & {$[86]$} \\
\hline
\end{tabular}

KRAS, K-Ras; SAT1, spearmidine/spermine N1-acetyltransferase 1; SLC13A2, solute carrier family 13, member 2; TMEM72, transmembrane protein 72; PSMB2, proteasome subunit beta type-2; EGRF, epidermal growth factor receptor. 


\section{Gestational diabetes mellitus}

Several classes of non-coding RNA have a significant role in gene regulation at the transcription-translational level of GDM pathogenesis. However, to date, the majority of the non-coding RNAs identified in GDM are miRNAs, which function by interfering with the translational process of mRNA [87]. Using RNA-sequencing (such as the Illumina HiSeq 250 platform), combined with qRT-PCR or microarrays (such as TaqMan miRNA array), or miRNA PCR array, most of the dysregulated miRNA activities are seen during the early second trimester of pregnancy of GDM patients [87], [88], [89], [90]. Most of the miRNAs were upregulated and only a minority was downregulated in GDM throughout the whole gestational period. The changes in blood miRNAs that are associated with GDM (based on trimesters) are listed in Table 5.

Table 5: Changes in blood microRNA associated with gestational diabetes mellitus.

\begin{tabular}{lllr}
\hline $\begin{array}{l}\text { Trimesters of } \\
\text { pregnancy }\end{array}$ & Upregulation & Downregulation & References \\
\hline Early second & $\begin{array}{l}\text { MiR-16-5p, MiR-17-5p, } \\
\text { MiR-19a-3p, MiR-19b-3p, }\end{array}$ & - & [88], [89] \\
& $\begin{array}{l}\text { MiR-20a-5p, MiR-330-3p } \\
\text { MiR-142, MiR-143, MiR-330-3p, } \\
\text { Late second }\end{array}$ & MiR-20a-5p, MiR-222-3p & \\
Third & MiR-143, MiR-340, MiR-let-7g & MiR-20a-5p, MiR-222-3p & [87], [89], [90] \\
\hline
\end{tabular}

In the early second trimester of pregnancy, miRNAs associated with insulin resistance, such as miR-16-5p, miR-17-5p, miR-19a-3p, miR-19b-3p and miR-20a-5p were found to be increased in the sera of GDM patients compared to non-GDM persons [88], [91]. However, the sensitivity of miR-16-5p, miR-17-5p and miR-20a-5p detection was only $41.6 \%, 21.4 \%$ and $17.8 \%$, respectively; while specificity was $95.8 \%, 98.4 \%$ and $95.4 \%$, respectively [91]. Interestingly, miR-20a-5p increased in the early second trimester of pregnancy but decreased in late second and third trimesters in GDM patients [88], [90]. In mice, it was found that miR-17-5p levels decreased in diabetic mice compared to non-diabetic mice [92]. This is due to the high glucose level that activates apoptosis signal-regulating kinase 1 by suppressing miR-17, resulting in increased gene expression of thioredoxininteracting protein [92]. Lately, the dysregulation of plasma miR-155-5p, miR-21-3p, miR-146b-5p, miR-223-3p, miR-517-5p and miR-29a-3p levels was found to be related to GDM patients in their early- and mid-term pregnancies and having male foetuses [93]. However, although the dysregulation of these plasma miRNAs was not found based on transcriptomics diagnostic tools, their diagnostic values could be considered.

In the late second and third trimesters of GDM patients, serum miR-20a-5p, which has a role in controlling insulin signalling, is significant reduced [90]. Interestingly, serum miR-222-3p amounts is significantly decreased in GDM but increased in T1D [67], [90]. On the other hand, a significant upregulation of miR-340 in the white blood cells of GDM patients is inversely associated with polyadenylate-binding protein-interacting protein 1 (PAIP1) levels [87]. According to Stirm et al., miR-340 expression changes with insulin and glucose levels in GDM by targeting PAIP1 gene expression [87]. However, there is a lack of functional studies of PAIP1 gene expression towards GDM. In addition to T2D, miR-143, which plays a part in mediating aerobic glycolysis, has been reported to marginally increase in GDM patients [87], [94]. Its overexpression leads to increased mitochondrial respiration and protein expression of mitochondrial complexes, and decreased expression of glycolytic enzymes in GDM [94]. The miRNA let-7g, a key player in glucose metabolism and insulin sensitivity [87], [95] was also found to be increased. In GDM, there is a genetic variation of rs3811463 (SNP near miR-let7 binding site in Lin28). This may alter the level of miR-let-7 and affect glucose uptake, glucose metabolism and insulin sensitivity [95]. The discovery of miRNAs and their potential roles in GDM may improve current screening and diagnostic strategies in GDM as they could further facilitate improvements to the current understanding of pancreatic $\beta$-cells dysfunction in GDM. Compared to the current methods, miRNAs could help in giving an earlier detection of dysregulation in glucose and insulin and dysfunction of pancreatic $\beta$-cells leading to GDM.

\section{Proteomics}

Proteomics is a high-throughput analysis of peptide or protein abundance in a cell, body fluid, or organism, including their structure, functions, modifications and interaction with others [28]. It utilises tools such as protein arrays [96] combined with mass spectrometry technologies and other protein separation techniques [97]. 


\section{Type 1 diabetes mellitus}

Although each autoantigen is regulated by miRNA, the production of autoantibodies by B-lymphocytes against these autoantigens is associated with some risk factors, such as age, gender and race. Up until now, the most common biomarkers in diagnosing T1D are islet autoantibodies (IA-2A, GADA, and ZnT8A) [34], [37]. Laterage onset of T1D is related to GADA, TPOA and PCA, but not TGA [34], [37]. In terms of having T1D duration, a shorter diabetic duration is found with GADA, IA-2A, ZnT8A, and TGA, but a longer duration is found with TPOA, PCA, and 21-OHA [34], [37]. In terms of gender, female T1D patients are associated with GADA, TPOA, PCA, and TGA [34], [37]. In terms of race, GADA is found more in African-Americans, while TGA is found in Native American [34]. The sensitivity and specificity of the three most common autoantibodies (ZnT8A, GAGA, and IA-2A) are listed in Table 6. Due to these variations, the need for identifying other protein biomarkers for the diagnosis of T1D is crucial.

Table 6: Sensitivity and specificity of the three most common autoantibodies in diabetes.

\begin{tabular}{lrrr}
\hline Autoantibodies & Sensitivity, $\%$ & Specificity, \% & References \\
\hline ZnT8A & 54 & 99 & {$[98],[99]$} \\
GADA & 67 & 98.9 & {$[98],[99]$} \\
IA-2A & 77 & 100 & {$[98],[99]$} \\
\hline
\end{tabular}

ZnT8A, Zinc transporter 8 autoantibody; GADA, glutamic acid decarboxylase autoantibody; IA-2A, insulinoma-2-associated autoantibody.

Recently, using proteomics diagnostic tools, six novel T1D autoantibodies have been identified using nucleic acid programmable protein array [100]. These autoantibodies are against protein tyrosine phosphatase, receptor type N2 (PTPRN2), mutL homolog 1 (MLH1), peptidyl-prolyl cis-trans isomerase-like 2 (PPIL2), nucleoporin 50, pyroglutamylated RFamide peptide receptor (QRFPR) and mitochondrial translational initiation factor 3 (MTIF3), with sensitivities ranging from 16 to $27 \%$ and a specificity of $95 \%$ [100]. The combination of using anti-MLH1, -PTPRN2, -PPIL2, and -QRFPR showed that the sensitivity increased to $37.5 \%$ in diagnosing T1D [100].

In addition to autoantibodies, serum adiposity proteins have been widely studied for their roles in T1D. It has been shown that several proteins, such as immune molecules and hormones, are linked to T1D. Although the validity of these proteins has yet to be determined through proteomics approach, they could be considered as the T1D biomarkers in future studies. The serum adiposity changes in T1D are listed in Table 7.

Table 7: Changes in serum adiposity of type 1 diabetes.

\begin{tabular}{llr}
\hline $\begin{array}{l}\text { Serum adiposity } \\
\text { Increases }\end{array}$ & Decreases & References \\
\hline $\begin{array}{l}\text { Proinflammatory adipokines, visfatis, } \\
\text { chemerin, adiponectin }\end{array}$ & $\begin{array}{l}\text { Anti-inflammatory adipokines, leptin, } \\
\text { omentin }\end{array}$ & [101], [102], [103], \\
\hline
\end{tabular}

\section{Type 2 diabetes mellitus}

Even though ZnT8A, IA-2A, GADA and insulin autoantibody (IAA) are also found in both T1D and T2D patients' sera [105], [106], T2D patients very rarely develop autoantibodies [107]. In addition, GADA and ZnT8A contribute to the progression towards T2D complications, polyneuropathy and nephropathy [105], while IAA and IA-2A are associated with obesity and overweightness in T2D complications [108]. Thus, these autoantibodies are not potential significant biomarkers in diagnosing T2D. Recently, a screening for potential serum proteomic biomarkers for T2D using matrix-assisted laser desorption/ionisation-mass spectrometry showed that fragments of complement C3f and kininogen 1 isoform 1 precursor are associated with T2D [109], with an accuracy of $82.20 \%$, sensitivity of $82.50 \%$ and specificity of $77.80 \%$ [109]. Moreover, using functional high-density protein microarray combined with the Luminex system, peroxisome proliferator-activated receptor gamma 2 (PPARG2) and NEDD8-conjugating enzyme Ubc12 (UBE2M) autoantibodies are found to be increased in T2D patients' sera (without HLA haplotype background HLA-DR $\beta 1^{*} 02$ ) compared to the normal control subjects (with HLA haplotype background) [110]. An individual having HLA-DR $\beta 1^{*} 02$ haplotype is protected from T2D as it is associated with increased insulin secretion as compared to an individual without the HLA haplo- 
type background [111]. PPARG2 has a sensitivity of $42 \%$, specificity of $78 \%$ and accuracy of $60 \%$ while UBE2M has a sensitivity of $33 \%$, specificity of $82 \%$ and accuracy of $58 \%$ [110]. Combining them had higher sensitivity $(51 \%)$, specificity $(82 \%)$ and accuracy $(67 \%)$ [110]. The PPARG protein has previously been reported to be associated with obesity, cardiovascular disease and cancer [112]. A higher level of prefoldin subunit 2 antibody (PFDN2A) is found in T2D patients' sera (without HLA haplotype background HLA-DR $\beta 11^{*} 02$ ), which has not been previously associated with T2D [113]. Prefoldin is responsible for the proper folding of protein structure and preventing aggregation [114], [115]. PFDN2A is more prevalent with early-age onset of T2D than late-onset [116].

Besides antibodies against islet antigens, other serum proteins could also serve as candidates for protein biomarkers of T2D. For example, leptin, retinol binding protein 4, pigment epithelium-derived factor and betatrophin levels are increased in T2D, whereas adiponectin and acute C-peptide levels are decreased [117], [118], [119], [120], [121], [122], [123]. Serum betatrophin is positively associated with blood pressure and serum fasting glucose and serves as a potential diagnostic biomarker for T2D as it shows a sensitivity of $83.56 \%$ and specificity of $72.41 \%$ [120], [122].

In addition to serum proteins, salivary proteins could be used as a diagnostic biomarker for T2D, although their levels are not as high as that of serum proteins [124]. A positive correlation of the proteins, such as $\alpha$ amylase and alpha-2-macroglobulin (A2MG), has been found between salivary and serum samples [124]. Moreover, salivary A2MG levels correlate to fasting blood glucose $(R=0.295$ vs $R=0.246)$ or $H_{b A_{1 c}}(R=0.443$ vs $R$ $=0.342$ ) better than plasma A2MG levels [125], [126], [127]. It is found to be up-regulated and has a detection sensitivity and specificity of $81.9 \%$ and $89.6 \%$, respectively [126], [127]. Hence, salivary A2MG may serve as a non-invasive marker for diabetes [125], although a proteomics approach could be pursued.

\section{Gestational diabetes mellitus}

Up to date, although the $\mathrm{HbA}_{1 \mathrm{c}}$ test is commonly recommended for T1D and T2D diagnosis, it has not been recommended for GDM diagnosis in any guideline, including WHO [16], [128]. In the past few years, much research has been devoted to the use of the $\mathrm{HbA}_{1 \mathrm{c}}$ test in diagnosing of GDM. However, these studies have revealed great limitations and drawbacks of the test. Many studies showed that $\mathrm{HbA}_{1 \mathrm{c}}$ levels are elevated in GDM patients compared to normal pregnant women in their second trimester [129], [130], [131]. However, the choice of the cut-off point in diagnosing GDM is based upon the trade-off between sensitivity and specificity. Higher cut-off values (34-40 mmol/ mol) yield lower sensitivity $(26.1-73.6 \%)$ but higher specificity $(77.2-94.9 \%)$, while lower cut-off values (34-29 mmol/mol) yield higher sensitivity (85.0-91.1\%) but lower specificity (31.862.0\%) [129], [130], [131], [132]. During their third trimester, the efficacy in diagnosing GDM using $\mathrm{HbA}_{1 \mathrm{c}}$ is low with moderate sensitivity (85.7\%) and poor specificity (61.1\%) [133]. As a comparison, by using OGT test, the current recommended test for GDM, the overall concordance between OGT test and $\mathrm{HbA}_{1 \mathrm{c}}$ results were poor during the third trimester of pregnancy [134]. Therefore, alternative biomarkers for the diagnosis of GDM are still required. Guo et al. found that the expressions of CD59 decreased and interleukin-1 receptor antagonist (IL1RA) increased in the urine of GDM women early in the second trimester, compared to normal pregnant women by using isobaric tags for relative and absolute quantification (iTRAQ) labelling, followed by quantitative proteomic tools, liquid chromatography-tandem mass spectrometry (LC-MS/MS) analysis and validation with enzyme-linked immunosorbent assay (ELISA) [135]. The IL1RA candidate biomarker performed more accurately when comparing to the CD9 marker, while combining them increased GDM prediction [135].

Recently, there are many other possible protein biomarkers for diagnosing GDM, which include glycoproteins, polypeptides, immune molecules, immunosuppressant molecules, neuropeptides, hormones, enzymes and receptors. Table 8 shows a list of possible serum protein biomarkers in the diagnosis of GDM. Most of the listed biomarkers are related to insulin resistance and glucose metabolism. These include afamin, cystatin-C, soluble pro-renin receptor (s[Pro]RR), tumour necrosis factor- $\alpha$ (TNF- $\alpha$ ), adiponectin, pregnancy-associate plasma protein-A (PAPP-A) and tumour necrosis factor-like weak inducer of apoptosis (TWEAK) [113], [136], [137], [138], [139], [140], [141], [142]. In addition, serum cyclophilin A (CyPA) correlates positively well with C-reactive protein concentration $(R=0.599)$ during the first trimester of pregnancy [143], although these findings were not via proteomics-based analysis. The discriminative potential of these biomarkers in diagnosing GDM in terms of diagnostic accuracy varies significantly. A summary of the sensitivities and specificities of serum protein biomarkers in predicting or diagnosing GDM is as in Table 9. 
Table 8: Possible candidate serum protein biomarkers in diagnosing gestational diabetes mellitus.

\begin{tabular}{lllr}
\hline Trimesters of pregnancy & Increased & Decreased & References \\
\hline First & Afamin, IL-6, hs-CRP, & Adiponectin, omentin-1, & {$[143],[144],[145],[146]$,} \\
& $\begin{array}{l}\text { glycosylated fibronectin. } \\
\text { cyclophilin A, s(Pro)RR }\end{array}$ & SHBG, irisin, PAPP-A & {$[147],[148],[149],[150]$,} \\
& & & {$[151],[152],[153],[154]$,} \\
Second & Afamin, cystatin-C, TNF- $\alpha$, & Irisin, SHBG \\
& galanin & & {$[155]$} \\
Third & - & TWEAK & {$[113],[138],[144],[145]$,} \\
\hline
\end{tabular}

IL-6, Interleukin 6; hs-CRP, high-sensitivity C-reactive protein; s(Pro)RR, soluble pro-renin receptor; TNF- $\alpha$, tumour necrosis factor- $\alpha$; SHBG, sex hormone-binding globulin; PAPP-A, pregnancy-associate plasma protein-A; TWEAK, tumour necrosis factor-like weak inducer of apoptosis.

Table 9: Sensitivity and specificity of serum protein biomarkers in predicting risk or diagnosing gestational diabetes mellitus.

\begin{tabular}{llcrr}
\hline $\begin{array}{l}\text { Trimesters of } \\
\text { pregnancy }\end{array}$ & Protein & Sensitivity, $\%$ & Specificity, \% & References \\
\hline \multirow{3}{*}{ First } & Adiponectin & 28.0 & 90.0 & {$[149]$} \\
& hs-CRP & 89.0 & 55.0 & {$[148]$} \\
& SHBG & 85.0 & 37.0 & {$[148]$} \\
& Glycosylayted & 81.0 & 90.0 & {$[149]$} \\
& fibronectin & & 70.0 & {$[150],[151]$} \\
Second & S(Pro)RR & 70.0 & 75.0 & {$[143]$} \\
& CyPA & 78.0 & 73.4 & {$[113]$} \\
& Cystatin-C & 58.6 & 90.0 & {$[160]$} \\
\hline
\end{tabular}

hs-CRP, High-sensitivity C-reactive protein; SHBG, sex hormone-binding globulin; s(Pro)RR, soluble pro-renin receptor; CyPA, cyclophilin A.

When combining two serum proteomic biomarkers, the accuracy in predicting or diagnosing GDM increases. For example, when using the adiponectin/TNF- $\alpha$ ratio, a decrease is a better indicator for the diagnosis of GDM than either alone [138]. Another example is combining sex hormone-binding globulin (SHBG) and high-sensitivity C-reactive protein (hs-CRP). A combination of low SHBG and high hs-CRP levels increased the sensitivity and specificity in predicting GDM to $74.07 \%$ and $75.62 \%$, respectively, compared to either indicator alone [148]. In contrast, glycosylated fibronectin alone gave a strong association to GDM status, whereas hsCRP and adiponectin only showed marginal association [149]. Therefore, in this case, glycosylated fibronectin represents a promising biomarker in screening the risk of developing GDM during the first trimester of pregnancy.

\section{Metabolomics}

Metabolomics is the large-scale study of metabolites present in a system (cell, tissue, or organism) at a given set of conditions to identify out-of-normal range perturbations of metabolites. Metabolites are small molecules $(<1500 \mathrm{Da})$, including amino acids, fatty acids, carbohydrates and other products associated with cellular metabolic functions [28]. The tools that are mainly associated in this study can be classified into either mass spectrometry-based or nuclear magnetic resonance (NMR)-based approaches [161].

\section{Type 1 diabetes mellitus}

The metabolic changes in diabetic patients are different from that of healthy individuals due to the dysfunction of the insulin receptor or the production of insulin. Recently, advanced glycation end-products (AGE) in skin is found to be related to long-term glycaemic control and complications in T1D patients, and it can be measured using skin autofluorescence (sAF) [162], [163], [164], [165]. It is higher in T1D children and non-white T1D patients due to elevated soluble receptor AGE (sRAGE) [163], [164], [166], [167]. AGE has been found to be 
related to $\mathrm{HbA}_{1 \mathrm{c}}$ and fasting plasma glucose [162], [164], [165], [166], [167]; and associated with retinopathy and albuminuria [162], [164]. Therefore, with a metabolomics approach, sAF may serve as a non-invasive method to measure AGE as a biomarker to diagnose T1D.

\section{Type 2 diabetes mellitus}

Similar to T1D metabolomics, the metabolic changes in diabetic patients are due to insulin resistance of organs. Metabolomics analysis, coupled with tandem mass spectrometry (MS/MS) tools, works very well in identifying potential diagnostic biomarkers for T2D from many different biological human samples, including serum, saliva, skin and urine [168], [169]. A summary of diagnostic biomarkers for T2D found in various biological samples is listed in Table 10.

Table 10: A summary of diagnostic biomarkers for type 2 diabetes found in various biological samples.

\begin{tabular}{lllr}
\hline Biological samples & Increased & Decreased & References \\
\hline Serum & - & $1,5-\mathrm{AG}$, X-11315 & {$[168]$} \\
Saliva & - & $1,5-\mathrm{AG}$, X-11315 & {$[168]$} \\
Urine & $1.5-\mathrm{AG}, 5^{\prime}$-MTA & $\begin{array}{l}\text { cAMP, acethylhistidine, } \\
\text { phenylalanine }\end{array}$ & {$[168],[169]$} \\
\hline
\end{tabular}

1,5-AG, 1,5-Anhydroglucitol; 5'-MTA, 5'-methylthioadenosine; cAMP, cyclic adenosine monophosphate.

1,5-Anhydroglucitol (1,5-AG) is a stable compound in blood. Many recent studies showed that 1,5-AG levels in the sera of T2D patients rapidly decrease; and the decrease is inversely correlated to glucose level $(\mathrm{R}=-0.470)$ [170], [171], [172]. As blood glucose level increases in T2D, it inhibits the reabsorption of 1,5-AG from kidney tubules by competing with it [173]. 1,5-AG is useful in providing short-term (3-7 days) glycaemic status of an individual and is associated with early phase insulin secretion [170], [172]. When used as a diagnostic marker, its sensitivity $(92.6 \%)$ and specificity $(82.3 \%)$ is higher than other glycaemic indicators [171]. Thus, it may serve as a potential diagnostic biomarker for T2D. However, it has poor diagnostic accuracy for GDM [174].

Saliva plays an important role in oral physiology [175]. It is a complex secretion composed of mainly water and few other components, such as glucose, proteins, nitrogenous products, and electrolytes, secreted by the salivary gland [176]. Multiple biochemical alterations including levels of glucose have been shown in saliva of diabetic patients [177], [178]. Using metabolomics approaches such as LC-MS/MS or gas chromatographytandem mass spectrometry (GC-MS/MS), 1,5-AG in saliva was found to be correlated with 1,5-AG in blood (R $=0.74)$, but inversely-correlated with blood glucose $(\mathrm{R}=-0.51)$ [168]. Just like in serum, saliva 1,5-AG provides a sensitivity of $90.3 \%$ and specificity of $78.4 \%$ when used as a diagnostic biomarker for T2D [168]. X-11315 in saliva, which was also detected in blood, is highly correlated with plasma 1,5-AG levels $(\mathrm{R}=0.54)$ [168]. The biochemical identity of this metabolite is still unknown [168]. In addition, in older people, using the ultraperformance liquid chromatography-tandem mass spectrometer (UPLC-MS/MS) approach, late-onset T2D had an elevated 5'-MTA level, but lower levels of cAMP, acetylhistidine and phenylalanine in their urine samples [169]. Comparing these 4 metabolites, in urine, 5'-MTA has the greatest change in late-onset T2D than nondiabetic individuals [169], which therefore may serve as a validated biomarker of T2D in human urine.

Another recent biological sample that could be used to diagnose T2D is breath. In breath, a high number of volatile organic compounds (VOCs) are derived from metabolic origins and are associated with one's health status and condition. VOCs can be detected using gas chromatography time-of-flight mass spectrometry (GC-TOF-MS) as a metabolomics approach [179], [180]. It is long known that acetone is one of the products formed due to ketosis of T1D and T2D [181], [182]. The sensitivity and specificity of breath acetone is 100\% and 97.7\%, respectively [183], [184]. However, there is great difficulty in detecting acetone levels as it exists in trace amounts. The use of 1-butyl-3-methylimidazolium tetrafluoroborate and quartz crystal microbalance sensor as diagnostic tools are able to detect acetone amongst VOCs in a breath test [185]. Hence, it is an example of a current development of a non-invasive sensor for early diabetes detection. Furthermore, ${ }^{13} \mathrm{C}$-enriched foods could replace ${ }^{13} \mathrm{C}$-labelled glucose in the breath test for the diagnosis of pre-diabetic and T2D, as the sensitivity and specificity is about $95 \%$ in detecting carbon dioxide levels in breath [186], [187]. 


\section{Gestational diabetes mellitus}

Metabolomics is also of great diagnostic value for GDM as the early disruption of many metabolites is seen to be associated with GDM. Many GDM-specific metabolites are found mostly in blood but some are in urine using metabolomics tools such as MS-associated tools [188], [189]. However, a number of factors such as dietary intake, daily activities and hormonal changes may affect the dynamic nature of the biofluid and hence potentially lead to result discrepancy. Thus, an alternative and stable biological sample may be better than blood and urine.

Among the metabolites, serum fatty acids and amino acids are strongly correlated with GDM [189], [190]. Increased levels of serum even-chain saturated fatty acid (SFA) and decreased levels of serum odd-chain SFA increase the risk of GDM in pregnant women [191]. The serum amino acids in GDM patients are mainly upregulated in all three trimesters of pregnancy, but the level of amino acids is different at each trimester [190], [192], [193], [194], [195]. An amino acid, valine, is increased in the second and third trimesters of pregnancy, as well as in postpartum GDM [188], [190], [195]. Valine plays a role in insulin resistance by promoting fatty acid uptake to muscle [196]. The continuous increase in valine level postpartum is a risk of T2D for GDM women [193]. Other serum metabolites that are changed in GDM include acylcarnitines, sugars and alcohols, organic acids and cholesterol [190], [193], [197]. As for urine, an increase in urinary ethylmalonate concentration is associated with an increase in the risk of GDM, whereas a decrease in urinary adipate increases the risk of GDM early in the second trimester of pregnancy [198]. Also, the change in serotonin-related metabolites in urine improves risk prediction accuracy in GDM [188]. All these metabolite changes found in GDM serum or urine may serve as predictive or early diagnosis biomarkers for GDM. Nevertheless, the diagnostic accuracy of each of these metabolites should be studied to confirm its potential.

Besides blood and urine, hair could serve as a non-invasive biological sample. Hair is a stable specimen and provides long-term metabolic information. Recent studies have gained interest in the use of hair as a biological sample for potential metabolic biomarkers in diagnosing GDM [199], [200]. Adipic acid is significantly higher in GDM compared to healthy pregnant women during the second trimester of pregnancy [199]. On the other hand, tryptophan and leucine are increased in GDM during the second trimester of pregnancy [200]. During the third trimester of pregnancy, tryptophan, leucine, citric acid, 3,4-oxaolidinercarboxylic acid, 2-oxovaleric acid, 3-pyridinecarboxamide and 2-oxobutyric acid are decreased in GDM, while 1-hydroxy-3-3-nonanone and 22-oxavitamine D3 are increased in GDM [200]. As hair metabolome research related to GDM is still at its infancy, more studies are required to confirm the use of metabolic changes in hair as a non-invasive metabolomic diagnostic biomarker for GDM.

\section{Metagenomics}

Metagenomics is a high-throughput gene level study recovered from environmental samples, in order to study a community of microorganisms. This allows high-resolution genomic analysis of microbes and correlation of genomes with particular functions in the environment, such as the human body [201]. A variety of sequencing tools, such as $16 \mathrm{~S}$ rRNA sequencing, whole genome sequencing and shotgun metagenomics sequencing may be used in metagenomics studies [201].

\section{Type 1 diabetes mellitus}

Gut microbes affect many biological functions in the body. By using 16S rRNA sequencing tool on HLA genotype-positive T1D stool samples combined with KEGG orthologues for functional characterisation, levels of gut microbe genes involved in carbohydrate metabolism, adhesions, motility, phages, prophages, sulphur metabolism and stress responses were higher in T1D, while genes involved in DNA and protein metabolism, aerobic respiration, and amino acid synthesis were higher in healthy individuals [202], [203]. At the phylum level, more Actinobacteria, Bacteroidetes and Proteobacteria were associated with T1D, while Firmicutes, Fusobacteria, Tenericutes and Verrucomicrobia were more in healthy individuals [202]. It was also reported that the number of Actinobacteria, Bacteroidetes, and Proteobacteria were increased, while Firmicutes was reduced in the faecal samples of T1D mice carrying the diabetogenic CD8 ${ }^{+} \mathrm{T}$ cell receptor [204].

At the genus level, by using 16S rRNA sequencing based on metagenomics linkage groups, the greatest change in the gut microbiome was seen between mucin-degrading bacteria (genera: Provotella) and short-chain fatty acids bacteria (genera: Bacteroides) [202]. Provotella spp. was found to present abundantly in healthy individuals but not in T1D patients, while Bacteroides spp. was abundant in T1D patients to compensate the loss of Provorella spp. [202]. Other bacteria such as short chain fatty acids producers (genera: Alistipes), lactate producers (genera: Lactobacillus, Lactococcus, Bifidobacterium, and Streptococcus) were more abundant in T1D 
patients' stools, while butyrate-producing bacteria (genera: Eubacterium, Fusobacterium, Anaerostipes, Roseburia, Subdoligranulum, and Faecalibacterium) and mucin-degrading bacteria (genera: Akkermansia) were more abundant in the stool samples of healthy individual [202], [205], [206]. Using shotgun metagenomic sequencing, other bacteria in addition to those previously stated were found to differ in the stool samples of T1D patients [203]. The number of long-chain triglycerides producers (genera: Blautia) and short-chain fatty acids producers (genera: Ruminococcus) were increased, while propionate producers (genera: Veillonella) was decreased in abundance in T1D patients [202], [203]. Complete absence of Coprococcus eutactus and Dialister invisus was noted in T1D patients [203]. On the other hand, 16S rRNA sequencing showed a decrease in the abundance of Bacteroides and Ruminococcus spp. members in mice harbouring protective alleles at the T1D-associated risk loci [207]. Bacteria such as Akkermansia and Faecalibacterium spp. decreased, while Ruminococcus and Streptococcus spp. increased in prediabetic persons' stools [208]. Akkermansia spp. differed the most in prediabetic conditions [208]. In T1D, a decreased Akkermansiamuciniphila population causes increased serum endotoxin levels and islet toll-like receptor expression, as well as decreased regulation of immunity [209].

\section{Type 2 diabetes mellitus}

Using $16 \mathrm{~S}$ rRNA sequencing on T2D patients' stool samples combined with KEGG and eggNOG orthologues for functional characterisation at the module and pathway levels, the gut microbiota involved in membrane transport of sugars, branched-chain amino acid (BCAA) transport, methane metabolism, xenobiotics degradation and metabolism and sulphate reduction were enriched in T2D patients [210]. By contrast, there was a decrease in the levels of bacterial chemotaxis, flagellar assembly, butyrate biosynthesis and metabolism of cofactors and vitamins [210]. Some important functions, including butyrate biosynthesis and sulphate reduction, coincided with the T2D-associated bacteria identified in the metagenomic linkage group analysis. The butyrate-producing bacteria seemed to be the primary contributors to cell motility [210].

In terms of categorisation by metagenomics linkage group, gut microbes such as the short chain fatty acids producers (genera: Bacteroides caccae) and sulphate-reducing species (genera: Desulfovibrio), were found enriched in T2D stool samples, while butyrate-producers (genera: Clostridium, Eubacterium, Faecalibacterium, and Roseburia), and mucin-degrading bacteria (genera: Akkermansia and Prevotella) were enriched in healthy patients but not the stools of T2D patients [210], [211], [212]. Also, Eggerthella lenta and Escherichia coli were reported to be enriched in T2D stool samples [210]. Whole genome shotgun gene sequencing, on the other hand, presented another bacterium that is less prevalent but showed changes in the stool of T2D patients are methane producers (genera: Methanobrevibacter) [212]. However, bacteria such as Clostridium, Akkermansia, and Faecalibacterium decreased, while Ruminococcus spp. increased in the stool of prediabetic individuals [208]. Clostridium and Akkermansia spp. differed the most in prediabetes [208]. Moreover, changes in gut microbes such as Bacteroides, Blautia, Alistipes and members of the phyla Firmicutes were found to be associated with obesity [212], [213]. Akkermansia muciniphilia had been reported to be negatively correlated with body mass index, fasting blood glucose and insulin levels, but positively-correlated with riboflavin and nicotinamide adenine dinucleotide biosynthesis [212]. On the other hand, Prevotella copri is linked to the risk of glucose intolerance and T2D [214].

\section{Gestational diabetes mellitus}

The microbiota of the oral cavity, vagina and intestine are greatly altered in GDM. GDM patients have more operational taxonomic units (OTUs) in at least two body sites compared to healthy pregnant women, and the largest changes occurred in the oral cavity with more Proteobacteria in GDM patients [215]. This indicates that a microbial shift in the maternal microbiota of different body sites could associate with GDM during pregnancy. Nevertheless, the human gut is still the most common site for microbiome imbalance in GDM patients [215], [216], [217], [218], [219]. Thus, the dysbiosis of gut microbiome may modulate the development of GDM and serve as a diagnostic biomarker for GDM.

At the phylum level, gut microbiome such as Actinobacteria, Proteobacteria and Firmicutes are taxonomic biomarkers of GDM, where Firmicutes is the most abundant phylum [219]. At the order level, Clostridiales decreases in GDM fecal samples [216]. At the genus and species level, GDM patients have increased Parabacteroides distasonis, Coprococcus comes, Bacteroides spp., Faecalibacterium spp., Prevotella spp., and unclassified Lachnospiraceae spp.; but healthy pregnant women have higher Roseburia spp., Fusobacterium spp., Haemophilus spp., Alistipes spp. (A. shahii and A. senegalensis), and Bifidobacterium spp. (B. animalis and B. pseudocatenulatum), as categorised by metagenomics linkage groups using whole-metagenome shotgun sequencing and 16S rRNA gene sequencing [216], [219].

In terms of functional composition by KEGG and eggNOG orthologues, the gut microbiome in GDM patients has a greater abundance of membrane transport, energy metabolism pathways, lipopolysaccharide, and 
phosphotransferase systems; while the gut microbiome in healthy pregnant women is more abundant in amino acid metabolic pathways [216]. In gestational glucose metabolism, insulin resistance and C-peptide are linked with phylum Actinobacteria and Firmicutes (such as Blautia spp.) [218], [219]. At species level, Lachnospiraceae spp., P. distasonis, Prevotella spp., and Faecalitalea spp. affect plasma glucose level, while Alistipes spp. has no effect [216], [219]. Bacteriodes spp. is associated with higher plasma hs-CRP but Alistipes spp. is related to lower hs-CRP [219].

In energy metabolism, higher serum leptin is related to members of the phylum Firmicutes (Family: Lachnospiraceae and Ruminococcaceae), whereas resistin is decreased in phylum Firmicutes (Family: Ruminococcaceae) [218]. Among all the gut microbiome, members of the Bacteroides or Parabacteroides genera have the highest discriminatory power between GDM patients and healthy pregnant women [216].

Although the pathogenesis of gut microbiome dysbiosis towards diabetes is not fully understood, but these data mainly showed lactate- and butyrate-producing bacteria in a healthy gut inducing a sufficient amount of mucin synthesis to maintain gut integrity. In contrast, non-butyrate-producing lactate-utilising bacteria (like short chain fatty acids and long-chain triglycerides producers) prevent optimal mucin synthesis, which causes diabetes. The information is useful as it may serve as an early diagnosis of diabetes prior to the clinical onset of disease. However, it is important to note that most studies of the taxonomic and functional signals detected in diabetic-control comparisons showed varying results due to geographic heterogeneity.

\section{Conclusions}

The search for diagnostic biomarkers in diabetes is rapidly expanding. Increasing efforts have been devoted to novel diabetes diagnostic biomarker discovery. However, most of the omics-based approach studies reviewed that biomarkers identified so far in T1D, T2D and GDM are mainly focused on serum samples. Nevertheless, non-invasive diagnostic biomarkers and tools have lately increased focusing on saliva, skin, breath, fecal and hair samples. Among all the omics-based biomarkers, proteomic biomarkers are identified the most in diagnosing diabetes. A summary of the strongest candidate biomarkers is shown in Table 11. Despite much efforts, the diagnostic accuracy and clinical usefulness of many biomarkers are yet to be fully validated. On top of that, there are limited studies done on the relationship between these biomarkers, diabetes development and the ability to differentiate the different types of diabetes.

Table 11: A summary of the strongest candidate diagnostic biomarkers in diagnosing diabetes.

\begin{tabular}{|c|c|c|}
\hline Omics & Types of diabetes & Biomarkers \\
\hline \multirow{3}{*}{ Genomics } & T1D & HLA-DR $\beta 1-H L A-D Q \alpha 1-H L A-D Q \beta 1$ region \\
\hline & $\mathrm{T} 2 \mathrm{D}$ & CDKAL1 region \\
\hline & GDM & CDKAL1 region \\
\hline \multirow{3}{*}{ Transcriptomics } & T1D & MiR-103 \\
\hline & $\mathrm{T} 2 \mathrm{D}$ & MiR-126 \\
\hline & GDM & MiR-20a-5p \\
\hline \multirow{3}{*}{ Proteomics } & T1D & Mitochondrial translational initiation factor 3 \\
\hline & $\mathrm{T} 2 \mathrm{D}$ & Peroxisome proliferator-activated receptor gamma \\
\hline & GDM & Adiponectin/TNF- $\alpha$ ratio \\
\hline \multirow{3}{*}{ Metabolomics } & T1D & soluble receptor AGE \\
\hline & $\mathrm{T} 2 \mathrm{D}$ & 1,5-Anhydroglucitol \\
\hline & GDM & Valine \\
\hline \multirow{3}{*}{ Metagenomics } & T1D & Butyrate-producing bacteria, short chain fatty acid bacteria, and \\
\hline & $\mathrm{T} 2 \mathrm{D}$ & mucin degrading bacteria \\
\hline & GDM & \\
\hline
\end{tabular}

T1D, Type 1 diabetes; T2D, type 2 diabetes; GDM, gestational diabetes mellitus; CDKAL1, cyclin-dependent kinase 5 regulatory subunit associated protein 1-like 1 ; TNF- $\alpha$, tumour necrosis factor- $\alpha$.

\section{Future directions}

Future research may focus more on non-invasive biomarkers as an alternative method in diagnosing diabetes, with validation on diagnostic accuracy. Furthermore, omics-based diagnostic tools to detect the various biomarkers should also be improved to be used as a standard-of-care practice. Moreover, more studies are 
needed to confirm the relationship of the biomarkers with diabetes pathophysiology and the potential ability in differentiating them. In order to do so, researchers could look into multi-omics approaches as they offer an opportunity to understand the flow of information that underlies disease, from the original cause of disease (genetic, environmental or developmental) to the functional consequences or relevant interactions instead of a single omics approach. Researchers should also focus on biomarkers for the transition from GDM to T2D. The potential diagnostic biomarkers stated in this article may also serve as therapeutic targets in treating diabetes.

\section{Acknowledgments}

The authors thank the Biomedical Science program, International Medical University, Malaysia for supporting this project.

\section{Research funding: None declared.}

Author contributions: All authors have accepted responsibility for the entire content of this manuscript and approved its submission.

Competing interests: Authors state no conflict of interest.

\section{References}

[1] American Diabetes Association. Diagnosis and classification of diabetes mellitus. Diabetes Care 2004;27:S5-10.

[2] NCD Risk Factor Collaboration. Worldwide trends in diabetes since 1980: a pooled analysis of 751 population-based studies with $4 \cdot 4$ million participants. Lancet 2016;387:1513-30.

[3] Whiting DR, Guariguata L, Weil C, Shaw ]. IDF diabetes atlas: global estimates of the prevalence of diabetes for 2011 and 2030. Diabetes Res Clin Pract 2011;94:311-21.

[4] Cuariguata L. By the numbers: new estimates from the IDF Diabetes Atlas Update for 2012. Diabetes Res Clin Pract 2012;98:524-5.

[5] Cuariguata L, Whiting D, Hambleton I, Beagley ], Linnenkamp U, Shaw ]. Global estimates of diabetes prevalence for 2013 and projections for 2035. Diabetes Res Clin Pract 2014;103:137-49.

[6] Ogurtsova K, da Rocha Fernandes ], Huang Y, Linnenkamp U, Guariguata L, Cho N, et al. IDF Diabetes Atlas: Global estimates for the prevalence of diabetes for 2015 and 2040. Diabetes Res Clin Pract 2017;128:40-50.

[7] Cho N, Shaw ], Karuranga S, Huang Y, da Rocha Fernandes ], Ohlrogge A, et al. IDF Diabetes Atlas: Clobal estimates of diabetes prevalence for 2017 and projections for 2045. Diabetes Res Clin Pract 2018;138:271-81.

[8] Beagley ], Guariguata L, Weil C, Motala AA. Global estimates of undiagnosed diabetes in adults. Diabetes Res Clin Pract 2014;103:150-60.

[9] IDF Diabetes Atlas Croup. Update of mortality attributable to diabetes for the IDF Diabetes Atlas: Estimates for the year 2013. Diabetes Res Clin Pract 2015;109:461-5.

[10] Harjutsalo V, Sjöberg L, Tuomilehto ]. Time trends in the incidence of type 1 diabetes in Finnish children: a cohort study. Lancet 2008;371:1777-82.

[11] Ostman ], Lonnberg G, Arnqvist H, Blohme G, Bolinder ], Ekbom Schnell A, et al. Cender differences and temporal variation in the incidence of type 1 diabetes: results of 8012 cases in the nationwide diabetes incidence study in Sweden 1983-2002. J Intern Med 2008;263:386-94.

[12] Barski L, Nevzorov R, Jotkowitz A, Rabaev E, Zektser M, Zeller L, et al. Comparison of diabetic ketoacidosis in patients with type-1 and type-2 diabetes mellitus. Am ] Med Sci 2013;345:326-30.

[13] Kim C, Newton KM, Knopp RH. Gestational diabetes and the incidence of type 2 diabetes: a systematic review. Diabetes Care 2002;25:1862-68.

[14] Verier-Mine O. Outcomes in women with a history of gestational diabetes. Screening and prevention of type 2 diabetes. Literature review. Diabetes Metab 2010;36:595-616.

[15] Black MH, Sacks DA, Xiang AH, Lawrence JM. The relative contribution of prepregnancy overweight and obesity, gestational weight gain, and IADPSG-defined gestational diabetes mellitus to fetal overgrowth. Diabetes Care 2013;36:56-62.

[16] American Diabetes Association. Classification and diagnosis of diabetes: Standards of medical care in diabetes-2018. Diabetes Care 2018;41:S13-27.

[17] Punthakee Z, Goldenberg R, Katz P, Diabetes Canada Clinical Practice Guidelines Expert Committee. Definition, classification and diagnosis of diabetes, prediabetes and metabolic syndrome. Can ] Diabetes 2018;42:S10-5.

[18] Sacks DB. A1C versus glucose testing: a comparison. Diabetes Care 2011;34:518-23.

[19] Kim SH, Park TS, Jin HY. Rethinking the accuracy of $75 \mathrm{~g}$ glucose used in the oral glucose tolerance test in the diagnosis and management of diabetes. Prim Care Diabetes 2017;11:555-60.

[20] Cavagnolli G, Pimentel AL, Freitas PA, Gross ]L, Camargo ]L. Effect of ethnicity on HbA1c levels in individuals without diabetes: Systematic review and meta-analysis. PLoS One 2017;12:1-14. 
[21] Christians U, Klawitter ], Klepacki ], Klawitter ]. Chapter three - The role of metabolomics in the study of kidney diseases and in the development of diagnostic tools. In: Edelstein CL, editor. Biomarkers of kidney disease, 2nd ed. Cambridge, Massachusetts: Academic Press, 2017:33-118.

[22] Velly AM, Mohit S, Schipper HM, Cornitsky M. Biomarkers in epidemiologic research: Definition, classification, and implication. In: Coulet JP, Velly A, editors. Orofacial pain biomarkers. Springer, Berlin, Heidelberg, 2017:135-39.

[23] Pepe MS, Janes H, Li Cl, Bossuyt PM, Feng Z, Hilden J. Early-phase studies of biomarkers: What target sensitivity and specificity values might confer clinical utility? Clin Chem 2016;62:737-42.

[24] Skyler ]S, Bakris CL, Bonifacio E, Darsow T, Eckel RH, Groop L, et al. Differentiation of diabetes by pathophysiology, natural history, and prognosis. Diabetes 2017;66:241-55.

[25] Adela R, Banerjee SK. Novel biomarkers to understand cardiovascular complications in diabetes. In: Mu W, Frank AW, editors. Role of biomarkers in medicine. London: InTech, 2016:93-117.

[26] Barh D, Blum K, Madigan MA. OMICS: biomedical perspectives and applications, 1st ed. Boca Raton: CRC Press, 2016.

[27] Karahalil B. Overview of systems biology and omics technologies. Curr Med Chem 2016;23:4221-30.

[28] Horgan RP, Kenny LC. 'Omic' technologies: genomics, transcriptomics, proteomics and metabolomics. Obstet Cynaecol 2011;13:189-95.

[29] Chuang HY, Hofree M, Ideker T. A decade of systems biology. Annu Rev Cell Dev Biol 2010;26:721-44.

[30] Voight BF, Kang HM, Ding ], Palmer CD, Sidore C, Chines PS, et al. The metabochip, a custom genotyping array for genetic studies of metabolic, cardiovascular, and anthropometric traits. PLoS Cenet 2012;8:e1002793-804.

[31] Cirulli ET, Coldstein DB. Uncovering the roles of rare variants in common disease through whole-genome sequencing. Nat Rev Genet 2010;11:415-25.

[32] Ng SB, Turner EH, Robertson PD, Flygare SD, Bigham AW, Lee C, et al. Targeted capture and massively parallel sequencing of 12 human exomes. Nature 2009;461:272-6.

[33] Cillespie KM, Aitken R], Wilson I, Williams A], Bingley P]. Early onset of diabetes in the proband is the major determinant of risk in HLA DR3-DQ2/DR4-DQ8 siblings. Diabetes 2014;63:1041-7.

[34] Brorsson CA, Pociot F. Type 1 Diabetes Cenetics Consortium. Shared genetic basis for type 1 diabetes, islet autoantibodies, and autoantibodies associated with other immune-mediated diseases in families with type 1 diabetes. Diabetes Care 2015;38:S8-13.

[35] Erlich H, Valdes AM, Noble ], Carlson JA, Varney M, Concannon P, et al. HLA DR-DQ haplotypes and genotypes and type 1 diabetes risk: analysis of the type 1 diabetes genetics consortium families. Diabetes 2008;57:1084-92.

[36] Hu X, Deutsch A], Lenz TL, Onengut-Gumuscu S, Han B, Chen W, et al. Additive and interaction effects at three amino acid positions in HLA-DQ and HLA-DR molecules drive type 1 diabetes risk. Nat Cenet 2015;47:898-905.

[37] Brorsson CA, Onengut S, Chen WM, Wenzlau ], Yu L, Baker P, et al. Novel association between immune-mediated susceptibility loci and persistent autoantibody positivity in type 1 diabetes. Diabetes 2015;64:3017-27.

[38] Christodoulou M, Avgeris M, Kokkinopoulou I, Maratou E, Mitrou P, Kontos CK, et al. Blood-based analysis of type-2 diabetes mellitus susceptibility genes identifies specific transcript variants with deregulated expression and association with disease risk. Sci Rep 2019;9:1512-25.

[39] Lowe WL, Scholtens DM, Sandler V, Hayes MC. Cenetics of gestational diabetes mellitus and maternal metabolism. Curr Diab Rep 2016;16:15-24.

[40] Groenewoud M, Dekker ], Fritsche A, Reiling E, Nijpels G, Heine R, et al. Variants of CDKAL1 and ICF2BP2 affect first-phase insulin secretion during hyperglycaemic clamps. Diabetologia 2008;51:1659-63.

[41] Stancáková A, Pihlajamäki ], Kuusisto ], Stefan N, Fritsche A, Häring H, et al. Single-nucleotide polymorphism rs7754840 of CDKAL1 is associated with impaired insulin secretion in nondiabetic offspring of type 2 diabetic subjects and in a large sample of men with normal glucose tolerance. J Clin Endocrinol Metab 2008;93:1924-30.

[42] Mao H, Li Q, Gao S. Meta-analysis of the relationship between common type 2 diabetes risk gene variants with gestational diabetes mellitus. PLoS One 2012;7:e45882-6.

[43] Zeng H, Guo M, Zhou T, Tan L, Chong CN, Zhang T, et al. An isogenic human ESC platform for functional evaluation of genome-wideassociation-study-identified diabetes genes and drug discovery. Cell Stem Cell 2016;19:326-40.

[44] Wei F, Suzuki T, Watanabe S, Kimura S, Kaitsuka T, Fujimura A, et al. Deficit of tRNA Lys modification by Cdkal1 causes the development of type 2 diabetes in mice. J Clin Invest 2011;121:398-608.

[45] Palmer C], Bruckner R], Paulo JA, Kazak L, Long JZ, Mina Al, et al. Cdkal1, a type 2 diabetes susceptibility gene, regulates mitochondrial function in adipose tissue. Mol Metab 2017;6:1212-25.

[46] Peng D, Wang ], Zhang R, Jiang F, Tam CH, Jiang G, et al. CDKAL1 rs7756992 is associated with diabetic retinopathy in a Chinese population with type 2 diabetes. Sci Rep 2017;7:8812-8.

[47] Yasuda K, Miyake K, Horikawa Y, Hara K, Osawa H, Furuta H, et al. Variants in KCNQ1 are associated with susceptibility to type 2 diabetes mellitus. Nat Genet 2008;40:1092-7.

[48] Demolombe S, Franco D, de Boer P, Kuperschmidt S, Roden D, Pereon Y, et al. Differential expression of KvLQT1 and its regulator IsK in mouse epithelia. Am J Physiol Cell Physiol 2001;280:C359-72.

[49] Ullrich S, Su J, Ranta F, Wittekindt OH, Ris F, Rösler M, et al. Effects of I Ks channel inhibitors in insulin-secreting INS-1 cells. Pflugers Arch 2005;451:428-36.

[50] Liu L, Wang F, Lu H, Ren X, Zou ]. Chromanol 293B, an inhibitor of KCNQ1 channels, enhances glucose-stimulated insulin secretion and increases glucagon-like peptide-1 level in mice. Islets 2014;6:1-8.

[51] Riobello C, Gómez ], Gil-Peña H, Tranche S, Reguero ]R, Jesús M, et al. KCNQ1 gene variants in the risk for type 2 diabetes and impaired renal function in the Spanish Renastur cohort. Mol Cell Endocrinol 2016;427:86-91.

[52] Huang K, Li T, Liu X, Chen ], Chien W, Shiao Y, et al. KCNQ1 variants associate with hypertension in type 2 diabetes and affect smooth muscle contractility in vitro. ] Cell Physiol 2017;232:3309-16.

[53] Kong Y, Sharma RB, Nwosu BU, Alonso LC. Islet biology, the CDKN2A/B locus and type 2 diabetes risk. Diabetologia 2016;59:1579-93. 
[54] Köhler CU, Olewinski M, Tannapfel A, Schmidt WE, Fritsch H, Meier ]]. Cell cycle control of $\beta$-cell replication in the prenatal and postnatal human pancreas. Am ] Physiol Endocrinol Metab 2010;300:E221-30.

[55] Helman A, Klochendler A, Azazmeh N, Gabai Y, Horwitz E, Anzi S, et al. p16 Ink4a-induced senescence of pancreatic beta cells enhances insulin secretion. Nat Med 2016;22(4):412-37.

[56] Salas E, Rabhi N, Froguel P, Annicotte ]S. Role of Ink4a/Arf locus in beta cell mass expansion under physiological and pathological conditions. ] Diabetes Res 2014;2014:1-7.

[57] Li H, Tang X, Liu Q, Wang Y. Association between type 2 diabetes and rs10811661 polymorphism upstream of CDKN2A/B: a meta-analysis. Acta Diabetol 2013;50:657-62.

[58] Rabhi N, Hannou SA, Gromada X, Salas E, Yao X, Oger F, et al. Cdknza deficiency promotes adipose tissue browning. Mol Metab 2018;8:65-76.

[59] Wouters K, Deleye Y, Hannou SA, Vanhoutte ], Maréchal X, Coisne A, et al. The tumour suppressor CDKN2A/p16INK4a regulates adipogenesis and bone marrow-dependent development of perivascular adipose tissue. Diab Vasc Dis Res 2017;14:516-24.

[60] Schulze A, Downward ]. Navigating gene expression using microarrays - A technology review. Nat Cell Biol 2001;3:E190-5.

[61] Ozsolak F, Milos PM. RNA sequencing: advances, challenges and opportunities. Nat Rev Genet 2011;12:87-98.

[62] Guo H, Ingolia NT, Weissman JS, Bartel DP. Mammalian microRNAs predominantly act to decrease target mRNA levels. Nature 2010;466:835-40.

[63] Nazarov PV, Reinsbach SE, Muller A, Nicot N, Philippidou D, Vallar L, et al. Interplay of microRNAs, transcription factors and target genes: linking dynamic expression changes to function. Nucleic Acids Res 2013;41:2817-31.

[64] Abuhatzira L, Xu H, Tahhan G, Boulougoura A, Schaffer AA, Notkins AL. Multiple microRNAs within the 14932 cluster target the mRNAs of major type 1 diabetes autoantigens IA-2, IA-2beta, and CAD65. FASEB ] 2015;29:4374-83.

[65] Garcia-Contreras M, Shah SH, Tamayo A, Robbins PD, Colberg RB, Mendez A], et al. Plasma-derived exosome characterization reveals a distinct microRNA signature in long duration type 1 diabetes. Sci Rep 2017;7:5998-6008.

[66] Collares CV, Evangelista AF, Xavier D], Rassi DM, Arns T, Foss-Freitas MC, et al. Identifying common and specific microRNAs expressed in peripheral blood mononuclear cell of type 1, type 2, and gestational diabetes mellitus patients. BMC Res Notes 2013;6:491-505.

[67] Erener S, Marwaha A, Tan R, Panagiotopoulos C, Kieffer T]. Profiling of circulating microRNAs in children with recent onset of type 1 diabetes. JCl insight 2017;2:e89656.

[68] Massaro JD, Polli CD, Costa E Silva MC, Alves CC, Passos CA, Sakamoto-Hojo ET, et al. Post-transcriptional markers associated with clinical complications in type 1 and type 2 diabetes mellitus. Mol Cell Endocrinol 2019;490:1-14.

[69] Osipova ], Fischer D, Dangwal S, Volkmann I, Widera C, Schwarz K, et al. Diabetes-associated microRNAs in pediatric patients with type 1 diabetes mellitus: a cross-sectional cohort study. J Clin Endocrinol Metab 2014;99:1661-5.

[70] Sims EK, Lakhter A], Anderson-Baucum E, Kono T, Tong X, Evans-Molina C. MicroRNA 21 targets BCL2 mRNA to increase apoptosis in rat and human beta cells. Diabetologia 2017;60:1057-65.

[71] Latreille M, Herrmanns K, Renwick N, Tuschl T, Malecki MT, McCarthy MI, et al. miR-375 gene dosage in pancreatic $\beta$-cells: implications for regulation of $\beta$-cell mass and biomarker development. J Mol Med 2015;93:1159-69.

[72] Barutta F, Bruno G, Matullo G, Chaturvedi N, Crimaldi S, Schalkwijk C, et al. MicroRNA-126 and micro-/macrovascular complications of type 1 diabetes in the EURODIAB prospective complications study. Acta Diabetol 2017;54:133-9.

[73] Meng S, Cao ], Zhang B, Zhou Q, Shen C, Wang C. Downregulation of microRNA-126 in endothelial progenitor cells from diabetes patients, impairs their functional properties, via target gene Spred-1. ] Mol Cell Cardiol 2012;53:64-72.

[74] Salas-Pérez F, Codner E, Valencia E, Pizarro C, Carrasco E, Pérez-Bravo F. MicroRNAs miR-21a and miR-93 are down regulated in peripheral blood mononuclear cells (PBMCs) from patients with type 1 diabetes. Immunobiology 2013;218:733-7.

[75] Nielsen LB, Wang C, Sørensen K, Bang-Berthelsen CH, Hansen L, Andersen MM, et al. Circulating levels of microRNA from children with newly diagnosed type 1 diabetes and healthy controls: evidence that miR-25 associates to residual beta-cell function and glycaemic control during disease progression. Exp Diabetes Res 2012;2012:896362.

[76] Yang M, Ye L, Wang B, Gao ], Liu R, Hong ], et al. Decreased miR-146 expression in peripheral blood mononuclear cells is correlated with ongoing islet autoimmunity in type 1 diabetes patients. J Diabetes 2015;7:158-65.

[77] Wan S, Wang ], Wang ], Wu ], Song ], Zhang C, et al. Increased serum miR-7 is a promising biomarker for type 2 diabetes mellitus and its microvascular complications. Diabetes Res Clin Pract 2017;130:171-9.

[78] Latreille M, Hausser ], Stützer I, Zhang Q, Hastoy B, Gargani S, et al. MicroRNA-7a regulates pancreatic $\beta$ cell function. ] Clin Invest 2014;124:2722-35

[79] Kornfeld ], Baitzel C, Konner AC, Nicholls HT, Vogt MC, Herrmanns K, et al. Obesity-induced overexpression of miR-802 impairs glucose metabolism through silencing of Hnfib. Nature 2013;494:111-5.

[80] Pescador N, Pérez-Barba M, Ibarra ]M, Corbatón A, Martínez-Larrad MT, Serrano-Ríos M. Serum circulating microRNA profiling for identification of potential type 2 diabetes and obesity biomarkers. PLoS One 2013;8:77251-8.

[81] Olivieri F, Spazzafumo L, Bonafe M, Recchioni R, Prattichizzo F, Marcheselli F, et al. MiR-21-5p and miR-126a-3p levels in plasma and circulating angiogenic cells: relationship with type 2 diabetes complications. Oncotarget 2015;6:35372-82.

[82] Higuchi C, Nakatsuka A, Eguchi ], Teshigawara S, Kanzaki M, Katayama A, et al. Identification of circulating miR-101, miR-375 and miR802 as biomarkers for type 2 diabetes. Metab Clin Exp 2015;64:489-97.

[83] Prabu P, Rome S, Sathishkumar C, Aravind S, Mahalingam B, Shanthirani CS, et al. Circulating MiRNAs of 'Asian Indian phenotype'identified in subjects with impaired glucose tolerance and patients with type 2 diabetes. PLoS One 2015;10:1371-84.

[84] Yan S, Wang T, Huang S, Di Y, Huang Y, Liu X, et al. Differential expression of microRNAs in plasma of patients with prediabetes and newly diagnosed type 2 diabetes. Acta Diabetol 2016;53:693-702.

[85] Zhang T, Li L, Shang Q, Lv C, Wang C, Su B. Circulating miR-126 is a potential biomarker to predict the onset of type 2 diabetes mellitus in susceptible individuals. Biochem Biophys Res Commun 2015;463:60-3.

[86] Lee Y, Joshipura K, Vergara ]L, Wong DT. Detection of type II diabetes mellitus using salivary transcriptomic biomarkers. Cenomic Medicine, Biomarkers, and Health Sciences 2012;4:7-11. 
[87] Stirm L, Huypens P, Sass S, Batra R, Fritsche L, Brucker S, et al. Maternal whole blood cell miRNA-340 is elevated in gestational diabetes and inversely regulated by glucose and insulin. Sci Rep 2018;8:1366-77.

[88] Zhu Y, Tian F, Li H, Zhou Y, Lu ], Ge Q. Profiling maternal plasma microRNA expression in early pregnancy to predict gestational diabetes mellitus. Int ] Gynaecol Obstet 2015;130:49-53.

[89] Sebastiani G, Guarino E, Grieco GE, Formichi C, Delli Poggi C, Ceccarelli E, et al. Circulating microRNA (miRNA) expression profiling in plasma of patients with gestational diabetes mellitus reveals upregulation of miRNA miR-330-3p. Front Endocrinol (Lausanne) 2017;8:345-56.

[90] Pheiffer C, Dias S, Rheeder P, Adam S. Decreased expression of circulating miR-20a-5p in South African women with gestational diabetes mellitus. Mol Diagn Ther 2018;22:345-52.

[91] Cao Y, Jia Y, Xing B, Shi D, Dong X. Plasma microRNA-16-5p,-17-5p and-20a-5p: Novel diagnostic biomarkers for gestational diabetes mellitus. J Obstet Cynaecol Res 2017;43:974-81.

[92] Dong D, Fu N, Yang P. MiR-17 downregulation by high glucose stabilizes thioredoxin-interacting protein and removes thioredoxin inhibition on ASK1 leading to apoptosis. Toxicol Sci 2015;150:84-96.

[93] Wander PL, Boyko E], Hevner K, Parikh V], Tadesse MG, Sorensen TK, et al. Circulating early- and mid-pregnancy microRNAs and risk of gestational diabetes. Diabetes Res Clin Pract 2017;132:1-9.

[94] Muralimanoharan S, Maloyan A, Myatt L. Mitochondrial function and glucose metabolism in the placenta with gestational diabetes mellitus: role of miR-143. Clin Sci (Lond) 2016;130:931-41.

[95] Liu Y, Ge Z, Sun L, Tong P, Lu H. Genetic variation of rs3811463 is associated with gestational diabetes mellitus susceptibility. Exp Ther Med 2017;14:5157-62.

[96] Kingsmore SF. Multiplexed protein measurement: technologies and applications of protein and antibody arrays. Nat Rev Drug Discov 2006;5:310-20.

[97] Yates ]R, Ruse Cl, Nakorchevsky A. Proteomics by mass spectrometry: approaches, advances, and applications. Annu Rev Biomed Eng 2009;11:49-79.

[98] Dunseath C, Ananieva-Jordanova R, Coles R, Powell M, Amoroso M, Furmaniak ], et al. Bridging-type enzyme-linked immunoassay for zinc transporter 8 autoantibody measurements in adult patients with diabetes mellitus. Clin Chim Acta 2015;447:90-5.

[99] Burbelo PD, Lebovitz EE, Bren KE, Bayat A, Paviol S, Wenzlau JM, et al. Extrapancreatic autoantibody profiles in type I diabetes. PLoS One 2012;7:45216-22.

[100] Bian X, Wasserfall C, Wallstrom C, Wang ], Wang H, Barker K, et al. Tracking the antibody immunome in type 1 diabetes using protein arrays. ] Proteome Res 2016;16:195-203.

[101] Hecht Baldauff N, Tfayli H, Dong W, Arena VC, Gurtunca N, Pietropaolo M, et al. Relationship of adiponectin and leptin with autoimmunity in children with new-onset type 1 diabetes: a pilot study. Pediatr Diabetes 2016;17:249-56.

[102] Cokulakrishnan K, Aravindhan V, Amutha A, Abhijit S, Ranjani H, Anjana RM, et al. Serum adiponectin helps to differentiate type 1 and type 2 diabetes among young Asian Indians. Diabetes Technol Ther 2013;15:695-701.

[103] Redondo M, Rodriguez L, Haymond M, Hampe C, Smith E, Balasubramanyam A, et al. Serum adiposity-induced biomarkers in obese and lean children with recently diagnosed autoimmune type 1 diabetes. Pediatr Diabetes 2014;15:543-9.

[104] Lohse Z, Bytoft B, Knorr S, Clausen TD, Jensen RB, Beck-Nielsen H, et al. Abnormal levels of adipokines in adolescent offspring of women with type 1 diabetes-Results from the EPICOM study. Metab Clin Exp 2017;72:47-56.

[105] Haller-Kikkatalo K, Pruul K, Kisand K, Nemvalts V, Reimand K, Uibo R. GADA and anti-ZnT8 complicate the outcome of phenotypic type 2 diabetes of adults. Eur ] Clin Invest 2015;45:255-62.

[106] Buzzetti R, Spoletini M, Zampetti S, Campagna G, Marandola L, Panimolle F, et al. Tyrosine phosphatase-related islet antigen 2(256760) autoantibodies, the only marker of islet autoimmunity that increases by increasing the degree of BMI in obese subjects with type 2 diabetes. Diabetes Care 2015;38:513-20.

[107] Leslie RD, Palmer ], Schloot NC, Lernmark A. Diabetes at the crossroads: relevance of disease classification to pathophysiology and treatment. Diabetologia 2016;59:13-20.

[108] Pilla S], Balasubramanyam A, Knowler WC, Lazo M, Nathan DM, Pi-Sunyer X, et al. Islet autoantibody positivity in overweight and obese adults with type 2 diabetes. Autoimmunity 2018;51:408-16.

[109] Meng Q, Ge S, Yan W, Li R, Dou ], Wang H, et al. Screening for potential serum-based proteomic biomarkers for human type 2 diabetes mellitus using MALDI-TOF MS. Proteomics Clin Appl 2017;11:1600079-88.

[110] Chang DC, Piaggi P, Hanson RL, Knowler WC, Bucci ], Thio G, et al. Use of a high-density protein microarray to identify autoantibodies in subjects with type 2 diabetes mellitus and an HLA background associated with reduced insulin secretion. PLoS One 2015;10:143551-64.

[111] Williams R, Muller Y, Hanson R, Knowler W, Mason C, Bian L, et al. HLA-DRB1 reduces the risk of type 2 diabetes mellitus by increased insulin secretion. Diabetologia 2011;54:1684-92.

[112] Aprile M, Ambrosio MR, D'Esposito V, Beguinot F, Formisano P, Costa V, et al. PPARG in human adipogenesis: Differential contribution of canonical transcripts and dominant negative isoforms. PPAR Res 2014;2014:537865-75.

[113] Zhao W, Pan ], Li H, Huang Y, Liu F, Tao M, et al. Relationship between high serum cystatin C levels and the risk of gestational diabetes mellitus. PLoS One 2016;11:147277-89.

[114] Takano M, Tashiro E, Kitamura A, Maita H, Iguchi-Ariga SM, Kinjo M, et al. Prefoldin prevents aggregation of $\alpha$-synuclein. Brain Res 2014:1542:186-94

[115] Cupta D, Leahy ]L. Islet amyloid and type 2 diabetes: overproduction or inadequate clearance and detoxification? ] Clin Invest 2014;124:3292-4.

[116] Chang DC, Piaggi P, Hanson RL, Knowler WC, Bogardus C, Krakoff]. Autoantibodies against PFDN2 are associated with an increased risk of type 2 diabetes: a case-control study. Diabetes Metab Res Rev 2017;33:2992.

[117] Weber K, Strassburger K, Pacini G, Nowotny B, Müssig K, Szendroedi ], et al. Circulating adiponectin concentration is inversely associated with glucose tolerance and insulin secretion in people with newly diagnosed diabetes. Diabet Med 2017;34:239-44 
[118] Umeno A, Yoshino K, Hashimoto Y, Shichiri M, Kataoka M, Yoshida Y. Multi-biomarkers for early detection of type 2 diabetes, including 10-and 12-(Z, E)-hydroxyoctadecadienoic acids, insulin, leptin, and adiponectin. PLoS One 2015;10:130971-86.

[119] Toloza F, Pérez-Matos M, Ricardo-Silgado M, Morales-Álvarez M, Mantilla-Rivas ], Pinzón-Cortés ], et al. Comparison of Plasma Pigment Epithelium-Derived Factor (PEDF), Retinol Binding Protein 4 (RBP-4), Chitinase-3-Like Protein 1 (YKL-40) and Brain-Derived Neurotrophic Factor (BDNF) for the identification of insulin resistance. J Diabetes Complications 2017;31:1423-9.

[120] Yi M, Chen R, Yang R, Guo X, Zhang ], Chen H. Betatrophin acts as a diagnostic biomarker in type 2 diabetes mellitus and is negatively associated with hdl-cholesterol. Int] Endocrinol 2015;2015:1-7.

[121] Hu H, Sun W, Yu S, Hong X, Qian W, Tang B, et al. Increased circulating levels of betatrophin in newly diagnosed type 2 diabetic patients. Diabetes Care 2014;37:2718-22.

[122] Al-Daghri NM, Rahman S, Sabico S, Amer OE, Wani K, Ansari MG, et al. Circulating betatrophin in healthy control and type 2 diabetic subjects and its association with metabolic parameters. J Diabetes Complications 2016;30:1321-5.

[123] Cokulakrishnan K, Manokaran K, Pandey CK, Amutha A, Ranjani H, Anjana RM, et al. Relationship of betatrophin with youth onset type 2 diabetes among Asian Indians. Diabetes Res Clin Pract 2015;109:71-6.

[124] Ladgotra A, Verma P, Raj SS. Estimation of salivary and serum biomarkers in diabetic and non diabetic patients-A comparative study. ] Clin Diagn Res 2016;10:56-61.

[125] Chung T, Hsu K, Chen ], Liu ], Chang H, Li P, et al. Association of salivary alpha 2-macroglobulin levels and clinical characteristics in type 2 diabetes. J Diabetes Investig 2016;7:190-6.

[126] Aitken ]P, Ortiz C, Morales-Bozo I, Rojas-Alcayaga G, Baeza M, Beltran C, et al. $\alpha$-2-macroglobulin in saliva is associated with glycemic control in patients with type 2 diabetes mellitus. Dis Markers 2015;2015:1-5.

[127] Feng ], Lu Y, Li ], Qi Y, Yi M, Ma D. Upregulation of salivary $\alpha 2$ macroglobulin in patients with type 2 diabetes mellitus. Cenet Mol Res 2015;14:2268-74.

[128] World Health Organization. Global report on diabetes. Switzerland: World Health Organization, 2016.

[129] Kwon SS, Kwon ], Park Y, Kim Y, Lim ]. HbA1c for diagnosis and prognosis of gestational diabetes mellitus. Diabetes Res Clin Pract 2015;110:38-43.

[130] Renz PB, Cavagnolli G, Weinert LS, Silveiro SP, Camargo JL. HbA1c test as a tool in the diagnosis of gestational diabetes mellitus. PLoS One 2015;10:135989-99.

[131] Ye M, Liu Y, Cao X, Yao F, Liu B, Li Y, et al. The utility of HbA1c for screening gestational diabetes mellitus and its relationship with adverse pregnancy outcomes. Diabetes Res Clin Pract 2016;114:43-9.

[132] Siricharoenthai P, Phupong V. Diagnostic accuracy of HbA1c in detecting gestational diabetes mellitus.] Matern Fetal Neonatal Med 2019;32:1-4.

[133] Rajput R, Rajput M, Nanda S. Utility of HbA1c for diagnosis of gestational diabetes mellitus. Diabetes Res Clin Pract 2012;98:104-7.

[134] Duke A, Yap C, Bradbury R, Hng TM, Kim C, Wansbrough A, et al. The discordance between HbA1c and glucose tolerance testing for the postpartum exclusion of diabetes following gestational diabetes. Diabetes Res Clin Pract 2015;108:72-7.

[135] Guo Y, Han Z, Guo L, Liu Y, Li G, Li H, et al. Identification of urinary biomarkers for the prediction of gestational diabetes mellitus in early second trimester of young gravidae based on iTRAQ quantitative proteomics. Endocr ] 2018;65:727-35.

[136] Seeber B, Morandell E, Lunger F, Wildt L, Dieplinger H. Afamin serum concentrations are associated with insulin resistance and metabolic syndrome in polycystic ovary syndrome. Reprod Biol Endocrinol 2014;12:88-94.

[137] Nagai Y, Ichihara A, Nakano D, Kimura S, Pelisch N, Fujisawa Y, et al. Possible contribution of the non-proteolytic activation of prorenin to the development of insulin resistance in fructose-fed rats. Exp Physiol 2009;94:1016-23.

[138] Khosrowbeygi A, Rezvanfar MR, Ahmadvand H. Tumor necrosis factor- $\alpha$, adiponectin and their ratio in gestational diabetes mellitus. Caspian ] Intern Med 2018;9:71-9.

[139] Ebert T, Hindricks ], Kralisch S, Lossner U, Jessnitzer B, Richter ], et al. Serum levels of fractalkine are associated with markers of insulin resistance in gestational diabetes. Diabet Med 2014;31:1014-7.

[140] Nyomba BG, Berard L, Murphy L]. Free insulin-like growth factor I (ICF-I) in healthy subjects: relationship with IGF-binding proteins and insulin sensitivity. J Clin Endocrinol Metab 1997;82:2177-81.

[141] Sesti C, Sciacqua A, Cardellini M, Marini MA, Maio R, Vatrano M, et al. Plasma concentration of ICF-I is independently associated with insulin sensitivity in subjects with different degrees of glucose tolerance. Diabetes Care 2005;28:120-5.

[142] Simón-Muela I, Llauradó C, Chacón MR, Olona M, Näf S, Maymó-Masip E, et al. Reduced circulating levels of TWEAK are associated with gestational diabetes mellitus. Eur ] Clin Invest 2015;45:27-35.

[143] Wang Z, Sun S, Chen Q, Li Y, Cai X. The first-trimester maternal serum cyclophilin a concentrations in women with complicated pregnancy as preeeclampsia. Clin Chim Acta 2018;484:105-10.

[144] Tramontana A, Dieplinger B, StangI C, Hafner E, Dieplinger H. First trimester serum afamin concentrations are associated with the development of pre-eclampsia and gestational diabetes mellitus in pregnant women. Clin Chim Acta 2018;476:160-6.

[145] Köninger A, Mathan A, Mach P, Frank M, Schmidt B, Schleussner E, et al. Is afamin a novel biomarker for gestational diabetes mellitus? A pilot study. Reprod Biol Endocrinol 2018;16:30-40.

[146] Abell SK, Shorakae S, Harrison CL, Hiam D, Moreno-Asso A, Stepto NK, et al. The association between dysregulated adipocytokines in early pregnancy and development of gestational diabetes. Diabetes Metab Res Rev 2017;33:2926.

[147] Zhang T, Du T, Li W, Yang S, Liang W. Sex hormone-binding globulin levels during the first trimester may predict gestational diabetes mellitus development. Biomark Med 2018;12:239-44.

[148] Maged AM, Moety CA, Mostafa WA, Hamed DA. Comparative study between different biomarkers for early prediction of gestational diabetes mellitus. J Matern Fetal Neonatal Med 2014;27:1108-12.

[149] Rasanen JP, Snyder CK, Rao PV, Mihalache R, Heinonen S, Gravett MC, et al. Glycosylated fibronectin as a first-trimester biomarker for prediction of gestational diabetes. Obstet Cynecol 2013;122:586-94.

[150] Cokulakrishnan K, Maheswari K, Mahalakshmi M, Kalaiyarasi G, Bhavadharini B, Pandey G, et al. Association of soluble (pro) renin receptor with gestational diabetes mellitus. Endocr Pract 2014;21:7-13. 
[151] Bonakdaran S, Azami G, Tara F, Poorali L. Soluble (pro) renin receptor is a predictor of gestational diabetes mellitus. Curr Diabetes Rev 2017:13:555-9.

[152] Sugulle M, Heidecke H, Maschke U, Herse F, Danser A], Mueller DN, et al. Soluble (pro) renin receptor in preeclampsia and diabetic pregnancies. J Am Soc Hypertens 2017;11:644-52.

[153] Wang P, Ma H, Hou X, Song L, Song X, Zhang ]. Reduced plasma level of irisin in first trimester as a risk factor for the development of gestational diabetes mellitus. Diabetes Res Clin Pract 2018;142:130-8.

[154] Beneventi F, Simonetta M, Locatelli E, Cavagnoli C, Badulli C, Lovati E, et al. Temporal variation in soluble human leukocyte antigen$\mathrm{G}$ (sHLA-G) and pregnancy-associated plasma protein A (PAPP-A) in pregnancies complicated by gestational diabetes mellitus and in controls. Am ] Reprod Immunol 2014;72:413-21.

[155] Wells G, Bleicher K, Han X, McShane M, Chan YF, Bartlett A, et al. Maternal diabetes, large for gestational age births, and first trimester pregnancy-associated plasma protein A. J Clin Endocrinol Metab 2015;100:2372-9.

[156] Yousefzadeh G, Pezeshki S, Cholamhosseinian A, Nazemzadeh M, Shokoohi M. Plasma cystatin-C and risk of developing gestational diabetes mellitus. Diabetes Metab Syndr 2014;8:33-5.

[157] Rueangdetnarong H, Sekararithi R, Jaiwongkam T, Kumfu S, Chattipakorn N, Tongsong T, et al. Comparisons of the oxidative stress biomarkers levels in gestational diabetes mellitus (GDM) and non-GDM among Thai population: cohort study. Endocr Connect 2018;7:681-7.

[158] Zhang Z, Gu C, Fang P, Shi M, Wang Y, Peng Y, et al. Endogenous galanin as a novel biomarker to predict gestational diabetes mellitus. Peptides 2014;54:186-9.

[159] Yuksel MA, Oncul M, Tuten A, Imamoglu M, Acikgoz AS, Kucur M, et al. Maternal serum and fetal cord blood irisin levels in gestational diabetes mellitus. Diabetes Res Clin Pract 2014;104:171-5.

[160] Khosrowbeygi A, Shiamizadeh N, Taghizadeh N. Maternal circulating levels of some metabolic syndrome biomarkers in gestational diabetes mellitus. Endocrine 2016;51:245-55.

[161] Dunn WB, Broadhurst DI, Atherton H], Coodacre R, Griffin JL. Systems level studies of mammalian metabolomes: the roles of mass spectrometry and nuclear magnetic resonance spectroscopy. Chem Soc Rev 2011;40:387-26.

[162] Cenevieve M, Vivot A, Gonzalez C, Raffaitin C, Barberger-Cateau P, Cin H, et al. Skin autofluorescence is associated with past glycaemic control and complications in type 1 diabetes mellitus. Diabetes Metab 2013;39:349-54.

[163] Bakker S, Tushuizen M, Gözütok E, Çiftci A, Gelderman K, Mulder C, et al. Advanced glycation end products (ACEs) and the soluble receptor for AGE (sRACE) in patients with type 1 diabetes and coeliac disease. Nutr Metab Cardiovasc Dis 2015;25:230-5.

[164] Rajaobelina K, Cougnard-Gregoire A, Delcourt C, Gin H, Barberger-Gateau P, Rigalleau V. Autofluorescence of skin advanced glycation end products: marker of metabolic memory in elderly population. ] Gerontol A Biol Sci Med Sci 2015;70:841-6.

[165] Noordzij M, Lefrandt ], Graaff R, Smit A. Skin autofluorescence and glycemic variability. Diabetes Technol Ther 2010;12:581-5.

[166] Banser A, Naafs ]C, Hoorweg-Nijman J], van de Garde EM, van der Vorst MM. Advanced glycation end products, measured in skin, vs. HbA1c in children with type 1 diabetes mellitus. Pediatr Diabetes 2016;17:426-32.

[167] van der Heyden JC, Josine C, Birnie E, Mul D, Bovenberg S, Veeze H], et al. Increased skin autofluorescence of children and adolescents with type 1 diabetes despite a well-controlled HbA1c: results from a cohort study. BMC Endocr Disord 2016;16:49-56.

[168] Mook-Kanamori DO, Selim MM, Takiddin AH, Al-Homsi H, Al-Mahmoud KA, Al-Obaidli A, et al. 1, 5-Anhydroglucitol in saliva is a noninvasive marker of short-term glycemic control. ] Clin Endocrinol Metab 2014;99:479-83.

[169] Tam ZY, Ng SP, Tan LQ, Lin CH, Rothenbacher D, Klenk ], et al. Metabolite profiling in identifying metabolic biomarkers in older people with late-onset type 2 diabetes mellitus. Sci Rep 2017;7:4392-403.

[170] Pramodkumar TA, Jayashri R, Cokulakrishnan K, Velmurugan K, Pradeepa R, Anjana RM, et al. Relationship of glycemic control markers $-1,5$ anhydroglucitol, fructosamine, and glycated hemoglobin among Asian Indians with different degrees of glucose intolerance. Indian J Endocrinol Metab 2016;20:690-5.

[171] Wang Y, Yuan Y, Zhang Y, Lei C, Zhou Y, He ], et al. Serum 1, 5-anhydroglucitol level as a screening tool for diabetes mellitus in a community-based population at high risk of diabetes. Acta Diabetol 2017;54:425-31.

[172] Ma X, Hao Y, Hu X, Luo Y, Deng Z, Zhou ], et al. 1, 5-Anhydroglucitol is associated with early-phase insulin secretion in Chinese patients with newly diagnosed type 2 diabetes mellitus. Diabetes Technol Ther 2015;17:320-6.

[173] Ma C, Sheng ], Liu Z, Guo M. Excretion rates of 1, 5-anhydro-D-glucitol, uric acid and microalbuminuria as glycemic control indexes in patients with type 2 diabetes. Sci Rep 2017;7:44291-5.

[174] Saglam B, Uysal S, Sozdinler S, Dogan OE, Onvural B. Diagnostic value of glycemic markers HbA1c, 1, 5-anhydroglucitol and glycated albumin in evaluating gestational diabetes mellitus. Ther Adv Endocrinol Metab 2017;8:161-7.

[175] Puy CL. The role of saliva in maintaining oral health and as an aid to diagnosis. Med Oral Patol Oral Cir Bucal 2006;11:449-55.

[176] Hernández-Castañeda AA, Aranzazu-Moya CC, Mora CM, Queluz DdP. Chemical salivary composition and its relationship with periodontal disease and dental calculus. Braz ] Oral Sci 2015;14:159-65.

[177] Babu NA, Masthan K, Bhattacharjee T, Elumalai M. Saliva-the key regulator of oral changes in diabetes patients. Int] Pharm Sci Res 2014;5:2579-83.

[178] Malik S, Khadgawat R, Anand S, Gupta S. Non-invasive detection of fasting blood glucose level via electrochemical measurement of saliva. Springerplus 2016;5:701-12.

[179] Baranska A, Tigchelaar E, Smolinska A, Dallinga JW, Moonen E], Dekens ]A, et al. Profile of volatile organic compounds in exhaled breath changes as a result of gluten-free diet. ] Breath Res 2013;7:037104.

[180] Dallinga JW, Smolinska A, van Schooten F. Analysis of volatile organic compounds in exhaled breath by gas chromatography-mass spectrometry combined with chemometric analysis. Methods Mol Biol 2014;1198:251-63.

[181] Stewart RD, Boettner EA. Expired-air acetone in diabetes mellitus. N Engl ] Med 1964;270:1035-8.

[182] Owen OE, Trapp VE, Skutches CL, Mozzoli MA, Hoeldtke RD, Boden G, et al. Acetone metabolism during diabetic ketoacidosis. Diabetes 1982;31:242-8 
[183] Zhou M, Liu Y, Li W, Yuan X, Zhan X, Li ], et al. Investigation and identification of breath acetone as a potential biomarker for type 2 diabetes diagnosis. Chin Sci Bull 2014;59:1992-8.

[184] Li W, Liu Y, Lu X, Huang Y, Liu Y, Cheng S, et al. A cross-sectional study of breath acetone based on diabetic metabolic disorders. ] Breath Res 2015;9:016005.

[185] Tao W, Lin P, Liu S, Xie Q, Ke S, Zeng X. 1-butyl-3-methylimidazolium tetrafluoroborate film as a highly selective sensing material for non-invasive detection of acetone using a quartz crystal microbalance. Sensors 2017;17:194-205.

[186] Chosh C, Mandal S, Pal M, Mukhopadhyay P, Ghosh S, Pradhan M. 13 C isotopic abundances in natural nutrients: a newly formulated test meal for non-invasive diagnosis of type 2 diabetes. ] Breath Res 2017;11:026005.

[187] Chosh C, Maity A, Banik CD, Som S, Chakraborty A, Selvan C, et al. Non-invasive 13C-glucose breath test using residual gas analyzermass spectrometry: a novel tool for screening individuals with pre-diabetes and type 2 diabetes. ] Breath Res 2014;8:036001.

[188] Leitner M, Fragner L, Danner S, Holeschofsky N, Leitner K, Tischler S, et al. Combined metabolomic analysis of plasma and urine reveals AHBA, tryptophan and serotonin metabolism as potential risk factors in gestational diabetes mellitus (CDM). Front Mol Biosci 2017;4:113.

[189] Dudzik D, Zorawski M, Skotnicki M, Zarzycki W, Kozlowska G, Bibik-Malinowska K, et al. Metabolic fingerprint of gestational diabetes mellitus. J Proteomics 2014;103:57-71.

[190] Enquobahrie DA, Denis M, Tadesse MG, Gelaye B, Ressom HW, Williams MA. Maternal early pregnancy serum metabolites and risk of gestational diabetes mellitus.] ] Clin Endocrinol Metab 2015;100:4348-56.

[191] Zhu Y, Tsai MY, Sun Q, Hinkle SN, Rawal S, Mendola P, et al. A prospective and longitudinal study of plasma phospholipid saturated fatty acid profile in relation to cardiometabolic biomarkers and the risk of gestational diabetes. Am ] Clin Nutr 2018;107:1017-26.

[192] Nevalainen ], Sairanen M, Appelblom H, Gissler M, Timonen S, Ryynanen M. First-trimester maternal serum amino acids and acylcarnitines are significant predictors of gestational diabetes. Rev Diabet Stud 2016;13:236-45.

[193] Roy C, Tremblay P, Anassour-Laouan-Sidi E, Lucas M, Forest ], Giguère Y, et al. Risk of gestational diabetes mellitus in relation to plasma concentrations of amino acids and acylcarnitines: A nested case-control study. Diabetes Res Clin Pract 2018;140:183-90.

[194] Rahimi N, Razi F, Nasli-Esfahani E, Qorbani M, Shirzad N, Larijani B. Amino acid profiling in the gestational diabetes mellitus. ] Diabetes Metab Disord 2017;16:13-8.

[195] Chorell E, Hall UA, Gustavsson C, Berntorp K, Puhkala ], Luoto R, et al. Pregnancy to postpartum transition of serum metabolites in women with gestational diabetes. Metabolism 2017;72:27-36.

[196] Andersson-Hall U, Gustavsson C, Pedersen A, Malmodin D, Joelsson L, Holmäng A. Higher concentrations of BCAAs and 3-HIB are associated with insulin resistance in the transition from gestational diabetes to type 2 diabetes. ] Diabetes Res 2018;2018:1-12.

[197] Miettinen HE, Rono K, Koivusalo S, Stach-Lempinen B, Poyhonen-Alho M, Eriksson JC, et al. Elevated serum squalene and cholesterol synthesis markers in pregnant obese women with gestational diabetes mellitus. ] Lipid Res 2014;55:2644-54.

[198] Qiu C, Enquobahrie DA, Frederick IO, Sorensen TK, Fernandez MA, David RM, et al. Early pregnancy urinary biomarkers of fatty acid and carbohydrate metabolism in pregnancies complicated by gestational diabetes. Diabetes Res Clin Pract 2014;104:393-400.

[199] He X, de Seymour JV, Sulek K, Qi H, Zhang H, Han T, et al. Maternal hair metabolome analysis identifies a potential marker of lipid peroxidation in gestational diabetes mellitus. Acta Diabetol 2016;53:119-22.

[200] Delplancke TD, Seymour JV, Tong C, Sulek K, Xia Y, Zhang H, et al. Analysis of sequential hair segments reflects changes in the metabolome across the trimesters of pregnancy. Sci Rep 2018;8:1-12.

[201] Chosh A, Mehta A, Khan AM. Metagenomic analysis and its applications. In: Ranganathan S, Gribskov M, Nakai K, Schönbach C, editors. Encyclopedia of bioinformatics and computational biology. Oxford: Academic Press, 2019:184-93.

[202] Brown CT, Davis-Richardson AG, Giongo A, Gano KA, Crabb DB, Mukherjee N, et al. Cut microbiome metagenomics analysis suggests a functional model for the development of autoimmunity for type 1 diabetes. PLoS One 2011;6:e25792-800.

[203] Kostic AD, Gevers D, Siljander H, Vatanen T, Hyötyläinen T, Hämäläinen A, et al. The dynamics of the human infant gut microbiome in development and in progression toward type 1 diabetes. Cell Host Microbe 2015;17:260-73.

[204] Tai N, Peng ], Liu F, Gulden E, Hu Y, Zhang X, et al. Microbial antigen mimics activate diabetogenic CD8 T cells in NOD mice. ] Exp Med 2016;213:2129-46.

[205] Paun A, Yau C, Meshkibaf S, Daigneault MC, Marandi L, Mortin-Toth S, et al. Association of HLA-dependent islet autoimmunity with systemic antibody responses to intestinal commensal bacteria in children. Sci Immunol 2019;4:eaau8125.

[206] Vatanen T, Franzosa EA, Schwager R, Tripathi S, Arthur TD, Vehik K, et al. The human gut microbiome in early-onset type 1 diabetes from the TEDDY study. Nature 2018;562:589-94.

[207] Mullaney JA, Stephens ]E, Costello M, Fong C, Ceeling BE, Gavin PG, et al. Type 1 diabetes susceptibility alleles are associated with distinct alterations in the gut microbiota. Microbiome 2018;6:35-50.

[208] Allin KH, Tremaroli V, Caesar R, Jensen BA, Damgaard MT, Bahl MI, et al. Aberrant intestinal microbiota in individuals with prediabetes. Diabetologia 2018;61:810-20.

[209] Hanninen A, Toivonen R, Poysti S, Belzer C, Plovier H, Ouwerkerk JP, et al. Akkermansia muciniphila induces gut microbiota remodelling and controls islet autoimmunity in NOD mice. Cut 2018;67:1445-53.

[210] Qin ], Li Y, Cai Z, Li S, Zhu ], Zhang F, et al. A metagenome-wide association study of gut microbiota in type 2 diabetes. Nature 2012;490:55-60.

[211] Tilg H, Moschen AR. Microbiota and diabetes: an evolving relationship. Cut 2014;63:1513-21.

[212] Yassour M, Lim MY, Yun HS, Tickle TL, Sung ], Song Y, et al. Sub-clinical detection of gut microbial biomarkers of obesity and type 2 diabetes. Genome Med 2016;8:17-30.

[213] Barlow GM, Yu A, Mathur R. Role of the gut microbiome in obesity and diabetes mellitus. Nutr Clin Pract 2015;30:787-97.

[214] De Filippis F, Pasolli E, Tett A, Tarallo S, Naccarati A, De Angelis M, et al. Distinct genetic and functional traits of human intestinal Prevotella copri strains are associated with different habitual diets. Cell Host Microbe 2019;25:444-53.

[215] Wang ], Zheng ], Shi W, Du N, Xu X, Zhang Y, et al. Dysbiosis of maternal and neonatal microbiota associated with gestational diabetes mellitus. Gut 2018;57:1614-25. 
[216] Kuang Y, Lu ], Li S, Li ], Yuan M, He ], et al. Connections between the human gut microbiome and gestational diabetes mellitus. Cigascience 2017;6:1-12.

[217] Hasan S, Aho V, Pereira P, Paulin L, Koivusalo SB, Auvinen P, et al. Gut microbiome in gestational diabetes: a cross-sectional study of mothers and offspring 5 years postpartum. Acta Obstet Cynecol Scand 2018;97:38-46.

[218] Comez-Arango LF, Barrett HL, McIntyre HD, Callaway LK, Morrison M, Dekker Nitert M, et al. Connections between the gut microbiome and metabolic hormones in early pregnancy in overweight and obese women. Diabetes 2016;65:2214-23.

[219] Crusell MK, Hansen TH, Nielsen T, Allin KH, Rühlemann MC, Damm P, et al. Cestational diabetes is associated with change in the gut microbiota composition in third trimester of pregnancy and postpartum. Microbiome 2018;6:1-19. 